\title{
Physiology of freezing of gait
}

A.H. Snijders, ${ }^{1,2}$ K. Takakusaki, ${ }^{3}$ B. Debu, ${ }^{4}$ A.M. Lozano, ${ }^{5}$ V.Krishna, ${ }^{5,6}$ A.Fasano, ${ }^{7}$

T.Z Aziz, ${ }^{8}$ S.M. Papa, ${ }^{9}$ S.A. Factor, ${ }^{9}$ M. Hallett ${ }^{10}$

${ }^{1}$ Department of Neurology, Donders Institute for Brain, Cognition and Behaviour, Radboud University Medical Centre, Nijmegen, The Netherlands, ${ }^{2}$ Maasziekenhuis Pantein, Boxmeer, The Netherlands, ${ }^{3}$ The Research Center for Brain Function and Medical Engineering, Asahikawa Medical University, ${ }^{4}$ Université Joseph Fourier, Grenoble Universités, Grenoble, France, ${ }^{5}$ Division of Neurosurgery, University of Toronto, Canada, ${ }^{6}$ Department of Neurosurgery, Ohio State University, Columbus, Ohio, USA, ${ }^{7}$ Morton and Gloria Shulman Movement Disorders Centre and the

Edmond J. Safra Program in Parkinson's Disease, Toronto Western Hospital, University Health Network, Toronto, ON, M5T 2S8, Canada, ${ }^{8}$ John Radcliffe Hospital, Headington, Oxford, United Kingdom, ${ }^{9}$ Department of Neurology, Jean and Paul

Amos Parkinson's disease and Movement Disorders Center, Emory University School of Medicine, Atlanta, USA, ${ }^{10}$ Human Motor Control Section, National Institute of Neurological Disorders and Stroke, National Institutes of Health, Bethesda, USA.

Correspondence to: A.H.Snijders, MD, PhD; Maasziekenhuis Pantein, Department of Neurology, Dokter Kopstraat 1, 5835 DV Beugen, The Netherlands; TEL: + 31-485 845000; FAX: + 31-485-845300; E-mail Address; A.Snijders@pantein.nl

Running title: Physiology of freezing of gait

Number of characters title / running head: 30

This article has been accepted for publication and undergone full peer review but has not been through the copyediting, typesetting, pagination and proofreading process which may lead to differences between this version and the Version of Record. Please cite this article as an 'Accepted Article', doi: 10.1002/ana.24778 
Word count: 6515

Number of figures: 5

Number of tables: 1
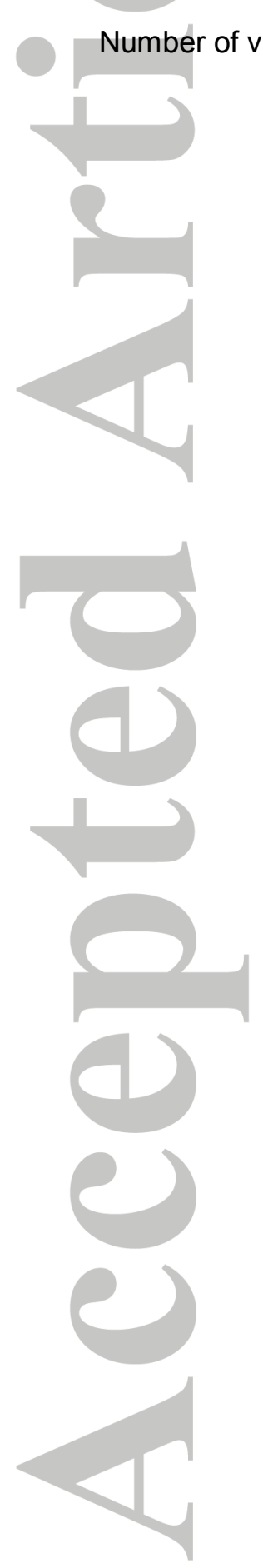

John Wiley \& Sons

This article is protected by copyright. All rights reserved. 


\section{Abstract}

Freezing of gait (FOG) is a common and debilitating, but largely mysterious, symptom of Parkinson's disease. In this review, we will discuss the cerebral substrate of FOG focusing on brain physiology and animal models. Walking is a combination of automatic movement processes, afferent information processing and intentional adjustments. Thus, normal gait requires a delicate balance between various interacting neuronal systems. To further understand gait control and specifically FOG, we will discuss the basic physiology of gait, animal models of gait disturbance including FOG, alternative etiologies of FOG and functional magnetic resonance studies investigating FOG. The outcome of these studies point to a dynamic network of cortical areas such as the supplementary motor area, as well as subcortical areas such as the striatum and the mesencephalic locomotor region (MLR) including the pedunculopontine nucleus (PPN). Additionally, we will review PPN (area) stimulation as a possible treatment for FOG, and ponder whether PPN stimulation truly is the right step forward.

\section{Abbreviations:}

CLR = cerebellar locomotor region; CNF = cuneiform nucleus; DBS = deep brain stimulation; FOG = Freezing of gait; MLR = Mesencephalic locomotor region; MTPT = 1-methyl-4-phenyl1,2,3,6-tetrahydropyridine; PPN = pedunculopontine nucleus; $P M=$ premotor area; SLR =subthalamic locomotor region; SMA = supplementary motor area; $\mathrm{SNr}=$ substantia nigra reticulata

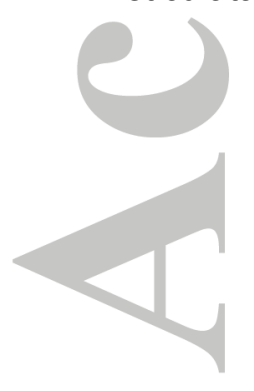




\section{Introduction}

Patients with Parkinson's disease (PD) often experience debilitating episodes of freezing of gait (FOG), during which their feet feel "glued to the floor"1, 2 FOG is defined "as a brief episode during which patients find it impossible to generate effective forward stepping movements, in the absence a cause other than parkinsonism or higher cortical deficits. It is most commonly experienced during turning and step initiation, but also when faced with special constraint such as a doorway, stress and distraction. Focused attention and external stimuli (cues) can overcome the episode. Because of its sudden and unpredictable nature, FOG often leads to falls and injuries."3 FOG presents itself in different phenomenologies. There are three subtypes: shuffling with small steps, trembling in place without forward movement, or total akinesia ${ }^{4}$. In addition, the effect of special constraints (such as going through doorways or stress) differs between patients. It remains an open question whether these phenomenologies are the result of different severity or represent different pathophysiologies. Most commonly FOG occurs in the OFF state, and may well be levodoparesponsive. However, the relationship with dopaminergic medication is complex, and as the disease progresses levodopa resistant FOG may develop. Paradoxically, sometimes FOG is even induced or worsened by dopaminergic medication. ${ }^{5}$ Freezing of upper limbs and of speech is correlated to FOG and bears remarkable spatiotemporal similarity; however, the added postural component renders FOG a distinct phenomenon. In this review, we will address the physiology of levodopa-responsive and levodopa-resistant FOG. We will discuss the current knowledge of the cerebral substrate of FOG as can be garnered using animal studies, animal and human 'models' of FOG and functional brain imaging. Although FOG can be seen in various diseases such as PD, multiple system atrophy, progressive supranuclear palsy or vascular disease, we will focus on FOG in PD.

Normal walking would seem to demand little attention. However, in actuality it is a complex task requiring a delicate balance between various interacting neuronal systems ${ }^{6}$. It necessitates not only automatic movement processes involving stepping and balance, but also attention, afferent information processing and intentional adjustments ${ }^{6-8}$. 
To further understand gait control and specifically FOG, we will first discuss the normal physiology of gait based on animal studies. Second, we will review animal models of gait disturbance including FOG. Next, the implications of alternative etiologies of FOG are discussed. We will show how functional magnetic resonance studies investigating FOG give insight to its physiology. The outcome of these animal and human studies point to the importance of cortical areas such as the supplementary motor area, as well as subcortical areas such as the striatum and the mesencephalic locomotor centre including the pedunculopontine nucleus (PPN). Last, we will review PPN stimulation as a possible treatment for FOG.

\section{Basic physiology of gait based on animal studies}

Lesioning studies have taught us important lessons concerning the cerebral control of locomotion. Multiple cat studies have used decerebration in which input from the brain is eliminated by cutting across different levels of the brainstem ${ }^{9}$. It has been shown that a decerebrate cat can still walk, trot and gallop. When the decerebration is made at precollicular-postmammillary level, the cat initiates locomotion only with electrical or chemical stimulation applied to the mesencephalic or midbrain locomotor region (MLR) ${ }^{10}$. However, if the neuraxis is transected slightly higher at the precollicular and premammillary level, cats can spontaneously elicit locomotion with well-coordinated postural control, accompanied by largely appropriate equilibrium control ${ }^{9}$. Therefore a critical region exists between these decerebrate levels. This area is recognized as the subthalamic locomotor region (SLR), which mostly corresponds to the lateral hypothalamic area. Stimulation of the SLR evoked locomotion after a large lesion was made in the MLR area ${ }^{11}$, indicating that the SLR has direct connections with the brainstem locomotor pathway beyond the MLR. However, the walking in the decerebrate preparations is machine-like and is neither goal-directed nor adaptive to the environment. Hence, the SLR connections to the MLR are likely important for normal gait. 
Lesions in the motor cortices in cats, just like pyramidal tract transection, elicited surprisingly minor deficits in locomotion. However, skilled performance is more severely disturbed by postcruciate than by precruciate lesions. The precruciate area, which corresponds to supplementary motor area (SMA) and premotor area (PM) of the primates, may be involved in movement initiation while the postcruciate cortices (posterior sigmoid gyrus) may utilize specific somatosensory inputs to regulate ongoing movements ${ }^{12}$ by anticipatory or feedforward adjustments ${ }^{13}$. Visuomotor integration is needed when an ambulating subject encounters obstacles, which requires involvement of the posterior parietal cortex ${ }^{14}$.

Another method for lesioning studies is to directly inject inhibitory substances into selected brain regions. In bipedal walking monkeys, inactivation of the leg region in primary motor cortex (M1) with injections of muscimol $\left(\mathrm{GABA}_{\mathrm{A}}\right.$ agonist) results in paresis of the contralateral leg ${ }^{15}$. On the other hand, injections into trunk or leg regions of the bilateral SMA largely disturb postural control without paralysis ${ }^{16}$. When injecting the dorsal PM, spontaneous walking is maintained, but no walking occurs following sensory guidance. While M1 mainly projects to the spinal cord, the SMA and PM have dense projections to the brainstem reticular formation ${ }^{17,18}$ including the PPN area ${ }^{19}$ in addition to projections direct to the spinal cord.

So far three locomotor regions have been identified in animals: the MLR, the SLR and the cerebellar locomotor region (CLR) in the mid-part of the cerebellum ${ }^{20}$. The MLR appears to be present in all classes of vertebrates ${ }^{21}$. It likely includes the cuneiform nucleus (CNF) and the PPN, although the precise location of the locomotor regulation still remains a matter of debate $^{22}$. A recent review offers a good overview of history, precise localization and interspecies differences of the MLR and $\mathrm{PPN}^{23}$. Importantly, the PPN is not just the 'cholinergic part of the MLR', although the cholinergic neurons serve to delineate PPN boundaries (pars compacta and pars dissipata). The PPN is located in the ventrolateral part of the caudal mesencephalic reticular formation, composed of a heterogeneous population of neurons, containing GABA and glutamate in addition to acetylcholine ${ }^{24}$. Different neuronal types within the PPN area have different functions with their own inter-connections to multiple parts of the 
brain. There are connections to cerebral cortex, multiple basal ganglia and limbic areas, the thalamus, the brainstem, the spinal cord and the cerebellum ${ }^{23}$. This key location including multiple segregate functions, renders determining the precise function of these regions quite complicated $^{25}$.

The PPN is active in suppressing muscle tone via its cholinergic projections to the pontine reticular formation, while the CNF mostly elicits locomotion. Microstimulation of the transition zone between the two areas (ventral CNF, dorsal PPN) induced a mixture of locomotor rhythm with associated muscle tone suppression ${ }^{26-30}$. Moreover, blocking the pontine reticular formation by injecting atropine sulfate, blocked the PPN-induced atonia but facilitated MLRinduced locomotion, indicating that cholinergic PPN neurons not only control the level of muscle tone but also modulate the locomotor pattern, and do this by effects at the pontine level $^{26}$. Studies in rats show non-cholinergic neurons just medial to the PPN have projections to the spinal cord, while the cholinergic neurons of the PPN do not. This area at the mesopontine junction may be the true MLR. In rats, the dorsal neurons of this MLR area (laterodorsal tegmental nucleus) with spinal projections are active in locomotion, while the ventral neurons are active in standing and do not have spinal projections ${ }^{22}$.

In the 'locomotor pathway', signals from the MLR also activate medullary reticulospinal neurons, in turn commanding the spinal locomotor network to generate the oscillatory pattern of locomotion ${ }^{31,32}$. However, the SLR and the CLR may also activate this reticulospinal locomotor pathway through distinct and direct projections ${ }^{33}$.(Figure 1B) Signals from the MLR may also activate monoaminergic descending pathways including the coerulospinal and raphespinal tracts, acting as a muscle tone excitatory system ${ }^{34-36}$.

An important consideration is how the neurons in these systems are controlled and modulated by neurons in other regions. We will now focus on the inputs of basal ganglia and motor cortices to the MLR area. In decerebrate cats, the basal ganglia control locomotion and posture using different GABAergic output pathways of the substantia nigra reticulata 
$(\mathrm{SNr})$; the lateral part of the SNr blocks the PPN-induced muscle tone suppression, whereas the medial part of the SNr suppresses the MLR-induced locomotion ${ }^{26,27,29}$. Recent rat studies confirm that inhibitory input from the SNc (GABAergic and dopaminergic) to ventral MLR regulate posture, while inhibitory projection from the GABAergic SNr to the dorsal MLR regulates locomotion ${ }^{22}$. In PD, GABAergic outputs of the basal ganglia are abnormally increased $^{37}$, so excessive SNr-inhibition of the MLR may cause gait disturbance and muscle rigidity $^{28,38}$. However, it is unknown whether these mechanisms are the same for bipedal humans and quadrupedal animals. Furthermore, it is unclear what drives or dictates the SNrinduced control of locomotion and posture. There are sub-compartments in the basal ganglia; neostriatum-dorsal pallidal pathway ("dorsal pathway") and ventral striatum-ventral pallidal pathway ("ventral pathway"). The nucleus accumbens, as a component of the limbic system, may be important in releasing locomotion, via GABAergic projections disinhibiting the MLR via the ventral pallidum ${ }^{39,40}$ and via fibers to the $\mathrm{SNr}^{41}$.(Figure 1B) Because the nucleus accumbens also receives inputs from the hippocampus and amygdala, the ventral pathway may be implicated in reward-oriented locomotor behaviors, as it receives inputs from ventral tegmental area, hippocampus and amygdala. On the other hand, the more recently evolved ${ }^{42}$ parts of the basal ganglia make up the dorsal system (Figure 1A). These parts may achieve locomotor control depending on cognitive behavioral context, such as sensory-guided locomotor control.

Studies using neural tracers have demonstrated abundant cortico-fugal projections to the brainstem reticular formation from the premotor cortices (SMA/PM) in quadruped ${ }^{18}$ and biped $^{17}$ animals. Recent studies have focused onto the importance of corticopedunculopontine projection in terms of motor control. The PPN receives partly separate but essentially convergent cortical inputs not only from multiple motor-related areas representing the same body part, but also from multiple regions representing diverse body parts ${ }^{43}$.

Probabilistic diffusion tractography in rhesus monkey as well as humans, shows that the 
SMA is strongly connected to the lateral PPN, while the dorsal PM is connected to the medial $\mathrm{PPN}^{19}$.

The SMA contributes to the anticipatory postural adjustment for step initiation, which is impaired in PD patients ${ }^{44}$ In the higher primate and, in particular, those with bipedal gait, SMA/PM projections to the PPN, in addition to the pontomedullary reticular formation, may play a crucial role of initiation of locomotion with appropriate postural control.

\section{Animal Models of FOG}

An important barrier to the discovery of the anatomic and biochemical correlates of FOG has been the lack of an appropriate animal model. Modeling FOG in animals is difficult because of its dependence on intentional motor performance and responses to environment. FOG requires that animals intend to walk during observation and the testing should include responses to obstacles and stressors. In addition, it is necessary to assess motion and associated physiologic parameters by using devices attached to hind legs, which is problematic in animals. Although these problems can be resolved with appropriate training, most animal models of PD or other FOG associated disorders are not suitable for extensive behavioral training due to compromised attention and learning. It is likely that "much of the research into experimental parkinsonism and dyskinesias must be undertaken in primates, for only those animals develop the typical clinical phenomena seen in man" ${ }^{\text {. }}$.

\section{Primate studies}

In 1983, several cases of parkinsonism in heroin users led to the discovery that the compound 1-methyl-4-phenyl- 1,2,3,6-tetrahydropyridine (MPTP) induces parkinsonism in humans $^{46}$. MPP+, the toxic metabolite of MPTP, is a mitochondrial complex I inhibitor that selectively kills dopaminergic neurons ${ }^{47}$ via uptake through the dopamine transporter. Thus, a primate model of parkinsonism was created that remains the only mammalian model to 
exhibit the whole motor phenotype of PD, including the resting tremor and drug-induced dyskinesias $^{48}$.

In descriptions of humans exposed to MPTP six of seven developed typical FOG ${ }^{49}$. The recent observation of FOG in MPTP intoxicated non-human primates is the first step in overcoming the deficiency of animal models ${ }^{50}$. Twenty-nine macaque monkeys were evaluated for FOG (12 male, mean age 4.3 years) after using a standard protocol of systemic intoxication with MPTP that produced moderate to severe parkinsonism ${ }^{50}$. For this study FOG was defined as episodic inability to generate effective stepping during walking. The monkeys had to be able to walk before and after the FOG episode. Fourteen of 29 (48\%) developed FOG in the hind limbs which had many of the characteristics typical of human FOG. The episodes lasted several seconds to a minute and were accompanied by a $4-10 \mathrm{~Hz}$ tremor similar to that seen in patients (Figure 2 and Video 1$)^{51}$. FOG was most consistently observed in the early morning prior to initiating dopaminergic medications. When the FOG occurred, the monkeys often would sit to break the episode, representing a possible trick. At the time of the publication of that report, FOG occurred in the off state in all but one animal in whom both on and off freezing was observed. However, since the publication of the initial observations L-dopa resistant FOG (during on and off state) has been found to be more prominent in animals with severe parkinsonism (unpublished data). Males were more likely to develop FOG, and the gait problem correlated with severity of parkinsonism and severity of levodopa-induced dyskinesia. Although the differences between humans and primates should of course be kept in mind, the study of both in this monkey model may provide greater insight into both levodopa responsive and unresponsive FOG in the human condition.

Pathological studies of MPTP induced parkinsonism in humans and non-human primates demonstrated changes in the dopaminergic system that recapitulate those seen in $\mathrm{PD}^{47}$. Studies in aged primates also demonstrated non-dopaminergic lesions seen specifically in the locus coeruleus, the primary source of norepinephrine ${ }^{52}$. In primate FOG thus far 
preliminary data suggests no significant neuronal loss in the PPN (unpublished data). The PPN is generally unaffected in younger MPTP intoxicated animals, but in some (not all) studies, there has been a loss of $20-30 \%$ PPN cholinergic neurons in aged MPTP treated monkeys ${ }^{53}$.

Attempted modeling in macaque monkeys combining lesioning the dopaminergic system with systemic MPTP intoxication and bilateral PPN injections of UII-Dtx (urotensin II-conjugated diphtheria toxin) to produce specific cholinergic lesions, did not succeed in provoking FOG. However, it did lead to gait disorders, disequilibrium and falls unresponsive to apomorphine ${ }^{54}$. These animals showed mostly postural instability and not FOG. Animal studies based on selective lesioning of the PPN will be discussed further in this review. However, none of the experiments identified have produced freezing. One might conclude to this point that while lesions of the PPN can lead to alterations in cadence of gait, balance and postural changes, it is unclear if there is a direct role in FOG.

\section{Rodent studies}

A study in rodents with cortical cholinergic and caudate dopaminergic lesions described significant propensity to falls pointing to the role of attentional impairment in gait disturbances ${ }^{55}$. Noteworthy, with larger dopaminergic lesion, dopamine loss extending across striatal regions (without the cholinergic lesion), gait abnormalities increase and rats also tend to slow or stop when traversing changing surfaces, leading to falls ${ }^{56}$. This tendency to stop and fall in rats with extensive dopamine depletion is congruent with the observed correlation between FOG and increased severity of parkinsonism in the primate ${ }^{50}$ as well as patients with PD. These studies did not address the impact of MLR involvement. However, a role of the PPN in FOG has been supported by a recent rodent study where bilateral dopaminergic lesions were combined with partial PPN destruction and the effects of stimulation on the anterior and posterior PPN areas were analyzed ${ }^{57}$. In this study, stimulation of the anterior PPN resulted in apparent freezing with start hesitation, while stimulation of the posterior region improved 
their gait. The freezing episodes in rats that were observed only in certain tasks (contextual gait), were not fully characterized and may not express the same parameters (tremor, timing, etc.) as of the FOG in PD. Still, rodent studies are important to assess the contribution of different brain regions in the control of gait. For example, another study in rodents implied that the more dorsal MLR may be more important for FOG. While lesioning the ventral MLR (pontine reticular formation) with OX-SAP toxin in rats induced typical cataplexy attacks, lesioning the dorsal MLR (laterodorsal tegmental nucleus) produced prolonged periods of immobility ${ }^{22}$. In contrast, stimulating this 'dorsal MLR' bilaterally with ibotenic acid caused continuous rhythmic walking and vocalizations ${ }^{22}$.

A recent study using optogenetics in mice showed that glutamatergic neurons in the MLR area are essential to initiate locomotion ${ }^{58}$. This experiment supports that cholinergic PPN neurons are not a critical element to initiate locomotion, but rather have a modulatory role. Another recent study in mice showed that the medullary reticulospinal system halted locomotion ${ }^{59}$. Together with the studies previously mentioned, we corroborate that basal ganglia output controls the excitability of the reticulospinal system to control locomotion via non-cholinergic (GABAergic and glutamatergic) and cholinergic neurons in the PPN/MLR area.

In addition, there is increasing evidence concerning the role of attentional performance through cholinergic projections of the forebrain in falls ${ }^{60}$.The basal forebrain has projections to the PPN ${ }^{61}$. In addition, it is often degenerated in PD patients ${ }^{62}$, which correlates with reduced walking speed ${ }^{63}$. Loss of cholinergic neurons in the basal forebrain and PPN in addition to the damage of midbrain dopamine neurons was associated with falls in PD ${ }^{64}$. Deciphering which of these is the primary source of falls, recent challenging experiments in rats point to the importance of the combination of basal forebrain cholinergic cell loss with striatal dopamine loss. Adding a selective cholinergic PPN lesion did not further deteriorate performance of the rats. ${ }^{56}$ Although these experiments point to the importance of the basal 
forebrain cholinergic - striatal disruption for falls, its role for freezing remains to be established.

Another step forward in animal modeling of FOG will be regional specific MLR lesions in the MPTP-treated monkey, to examine if they actually generate or enhance primate FOG. It would be critical to determine and quantify the changes in MLR cholinergic, glutaminergic and other neuronal subpopulations that may be associated with the development of FOG in primates as a next step toward mechanistic studies of the FOG pathophysiology.

\section{Functional MRI studies in humans with freezing of gait}

Imaging studies in subjects with FOG are also important tools in unraveling the physiology of this gait disorder. We will focus on what functional MRI (fMRI) studies during action teach us about the cerebral substrate of FOG, with a special focus on the PPN region / the MLR. In addition, we will discuss how to interpret the outcomes of different fMRI paradigms.

Functional MRI measures changes in cerebral blood flow related to neural activity, while the subject is lying in an fMRI scanner. Creative solutions have been found to solve the limitation that walking is not possible during scanning. These solutions include the use of motor imagery of gait, virtual reality in combination with alternating leg movements and freezing of finger movements as alternatives to freezing while walking.

The first fMRI study in PD subjects with FOG investigated gait planning, using motor imagery of walking ${ }^{65}$. This approach exploits the large neural overlap that exists between planning and imagining a movement. In addition, it avoids the confounds introduced by brain responses to altered motor performance and somatosensory feedback during actual freezing episodes. Twelve PD-freezers, twelve matched PD non-freezers and 21 matched healthy controls were studied. Subjects performed two validated tasks: motor imagery of gait, and a visual imagery control task. Imagery performance was quantified by measuring the time 
required to imagine walking on paths of different width and length, and showed matched task performance. During motor imagery of gait, freezers showed more activity than non-freezers in the MLR. Freezers also tended to have decreased responses in mesial frontal and posterior parietal regions. The gait-related hyperactivity of the MLR correlated with clinical parameters (FOG severity and disease duration). The hyperactivity was located dorsally in the MLR, including the PPN but with a local maximum in the cuneiform nucleus and reaching the periaqueductal grey. Another study using motor imagery of gait on 9 PD freezers versus 9 PD non-freezers showed a decrease in right globus pallidus and trends to a similar decrease in SMA activity in those with FOG $^{66}$. However, this study did not show PPN hyperactivity (they actually showed a trend to hypo-activity), while using a stereotactically defined region of interest analysis of the PPN with the local maximum slightly more caudal to the area found in the first study (Talairach coordinates ${ }^{65} \mathrm{X}-0, \mathrm{Y}-28, \mathrm{Z}-15,{ }^{66} \mathrm{X} \pm 6, \mathrm{Y}-26, \mathrm{Z}-$ 11)

When considering motor imagery studies, it should be taken into account that they may investigate motor planning and not motor execution. In addition, patients imagined they were walking, but not having FOG episodes. Another approach that looked at actual motor execution and not planning, investigated repetitive hand movements with upper limb freezing ${ }^{67}$. Upper limb freezing has been shown to be similar to leg freezing and correlated to $\mathrm{FOG}^{68,69}$. In an fMRI study, 16 PD freezers, 16 PD non-freezers and 16 controls performed a bimanual flexion-extension task of the index fingers. During regular movement, freezers showed decreased activity in cortical regions in the left dorsal premotor and primary motor cortex, as well as the right dorsolateral prefrontal cortex. In addition, those with FOG showed subcortical bilateral activation of STN, putamen and pallidum during regular movement. Comparing regular movement with freezing of upper limb episodes, upper limb motor blocks were associated with increased activation in the right motor cortex, dorsal premotor cortex, SMA and left prefrontal cortex, whereas bilateral pallidum and putamen activity was decreased. MLR involvement would not be expected in these studies. 
A third approach also investigated non-gait repetitive movements, specifically alternate leg movements in a virtual reality walking environment. This approach showed by increasing cognitive load during continuous movement, a decreased activity in the ventral striatum, preSMA and left STN ${ }^{70}$. During motor blocks, a decreased in dorsolateral prefrontal cortex, increase in frontoparietal and decrease in bilateral caudate, GPi and thalamus were found. In addition, a decrease in MLR activity (almost same maximum as ${ }^{65}$ ) was found which correlated to the severity of $\mathrm{FOG}^{71}$. The outcome of these studies point to the importance of cortical areas, particularly the SMA, as well as subcortical areas including the striatum and the MLR.

Beyond the individual role of these separate regions, it shows the importance of their interplay and communication through different neural networks. It appears to be a dynamic process (Figure 3): during continuous movement cortical activity is decreased and (compensatory to this decreased cortical activity?) subcortical activity is increased (MLR for the legs, STN for the hands). During subsequent episodes of freezing (of upper or lower limb) the STN and MLR hyperactivity breaks down to hypoactivity. Subsequent increased activity in dorsolateral prefrontal cortex and insula may be called upon to overcome the block but may play a role in subsequent emotional response as well. This failing dynamic process leading to freezing might become particularly evident during challenging events that require precise regulation of step length and gait timing, such as turning or initiating walking, which are well known triggers for FOG ${ }^{72}$ In this regard, greater resting state functional connectivity between the SMA and the MLR positively correlates to FOG severity, possibly reflecting a maladaptive neural compensation ${ }^{73}$. Indeed, the changes found in cerebral blood flow may well be compensatory and not reflect the primary pathological process. FOG may be caused by a combination of altered brain activity with impaired ability to compensate for that alteration. This may explain the manifestation of FOG during changes in motor behaviour, such as turning or initiating walking. These gait adaptations not only require a switch of motor program, but also more precise regulation of step length, gait timing and postural 
adjustments $^{65}$. It should be taken into account that all fMRI studies investigated levodoparesponsive freezers. Hence, in levodopa-resistant FOG, compensation may be further impaired.

Beyond fMRI, intrasurgical single unit recordings of (supposed) PPN and STN in PD patients give more insight to this complicated dynamic process. Recent investigations reveal the presence of both alpha and beta oscillations within the $\mathrm{PPN}^{74-80}$. Beta oscillations were identified within rostral PPN while alpha oscillations are more prominent in caudal $\operatorname{PPN}^{76,79}$, ${ }^{80}$. In general alpha oscillations were facilitatory for movements while beta oscillations were antikinetic $^{76-78}$. Task-related modulation of PPN activity is shown to be spatially-specific:

during motor imagery of gait, alpha and beta band power is increased mostly in the intermediate and dorsal part of the rostral PPN (around the inferior colliculus) ${ }^{80}$. In contrast, the STN mostly changes activity on real executed hand movements ${ }^{80}$. Another study showed more caudal PPN alpha activity to correlate with gait function. ${ }^{76}$ It should be noted that these studies were performed in the diseased and not in the healthy state. In addition, even within the PPN, different cells on the same spot are connected to different networks ${ }^{79}$. To reliably intervene in this complicated process will be a tremendous challenge.

\section{Primate research and interfering with the PPN}

The MLR is clearly important for gait, and its PPN component has generated much attention in relation to motor disorders ${ }^{81}$. It also has involvement in other functions including the regulation of cortical activity, sleep and diurnal rhythms, attention, learning and reward. In recent years, studies in the non-human primate have suggested that dysfunction of the PPN is at least partly responsible for axial motor symptoms of PD and that PPN stimulation may improve gait and postural control in patients with PD.

Early studies revealed that there is significant degeneration of PPN neurons in patients with advanced PD and in patients with multiple system atrophy with severe akinesia ${ }^{82,83}$. The 
extent of neuronal loss in the PPN corresponds to the degree of loss of dopaminergic neurons in the substantia nigra compacta in PD. There is also some correlation between the degree of degeneration in the PPN and the severity of PD symptoms ${ }^{83}$.

In non-human primates, unilateral lesioning of the PPN leads to a hemi-Parkinsonian state that resolves over time, whereas bilateral lesions in the PPN lead to a much more severe and permanent Parkinsonian state ${ }^{84,85}$. However, the gait disorder seen with PPN lesions is mostly postural instability and not $\mathrm{FOG}^{80}$.

Another step forward was to electrically (macro) stimulate the PPN in normal primates ${ }^{86}$ After stereotactic implantation of a DBS electrode unilaterally in the PPN in a normal macaque, no adverse effects on the motor performance of the animal were demonstrated. When subsequent trials of stimulation were performed (multiple sessions at several different frequencies ranging from 5 to $100 \mathrm{~Hz}$ ), there was a significant decrease in motor activity with higher frequency DBS (45 to $100 \mathrm{~Hz}$; Figure 4). There was also loss of postural control with $100 \mathrm{~Hz}$ stimulation. Lower frequency $(5$ to $10 \mathrm{~Hz})$ stimulation caused contralateral arm tremor $^{87}$. This could be confounded by the close proximity of the superior cerebellar peduncle. This series of experiments also established the practical feasibility of chronic DBS of the PPN by a fully implanted system with no significant adverse effects-an important consideration for further primate studies and possible clinical application.

Activating the PPN by injection of GABA antagonists leads to improvement of motor activity in post-MPTP animals. In a series of experiments a stereotactically implanted stainless steel cannula was placed into the unilateral PPN of a macaque $(n=2)$ was held in place with dental acrylic (Figure 4). The activity of the PPN was then modulated with sequential injections of GABA agonist muscimol, GABA antagonist bicuculline and saline (control). The injections were then repeated after the monkey was rendered parkinsonian with intravenous MPTP. Motor activity was recorded using automated activity counts, clinical scoring and blinded videotape assessments ${ }^{88}$. In the pre-MPTP state, inhibition of PPN using muscimol significantly reduced the activity of the monkey. In the post-MPTP animal, PPN stimulation using bicuculline significantly increased the overall motor activity. Moreover, it also improved 
balance and posture. These experiments again demonstrated that inhibition of the PPN leads to akinesia. They further established that stimulation of the PPN in the parkinsonian state can lead to increased activity and reversal of other axial symptoms like postural control.

Moreover, both sets of experiments demonstrated marked bilateral clinical effect from unilateral manipulation of the PPN.

Axial symptoms in advanced PD generally respond poorly to current medical and surgical treatments, including STN and GPi DBS. To establish the feasibility of treating advanced PD with marked axial symptoms with PPN DBS, a DBS lead was stereotactically inserted into the PPN of monkey's $(n=2)$ and connected to the fully implanted internal pulse generator. Serial stimulation experiments were performed. The animals were then made parkinsonian with intravenous MPTP and DBS repeated ${ }^{89-91}$. The results showed that low frequency PPN DBS (5 to $10 \mathrm{~Hz}$ ) improved the activity of the MPTP-monkeys. Moreover, when PPN DBS and L-Dopa treatment were combined, the activity of the monkeys was significantly greater than either treatment given alone. Based upon these observations clinical translation rapidly followed.

T.

\section{PPN: Potential for treating FOG}

World-wide, approximately 100 patients have received DBS of the PPN area ${ }^{92}$. The data referred to here should be considered PPN area rather than PPN since precise localization is difficult (See figure 5 for localization). Most human studies reported gait improvement with low frequency $(10-25 \mathrm{~Hz})$ stimulation although with a significant heterogeneity within and across studies (Table 1). Some studies show improvement of axial symptoms during $\mathrm{ON}^{93}$ or $\mathrm{OFF}^{94}$ with reduction of falls ${ }^{94,95}$. Low frequency stimulation $(10-25 \mathrm{~Hz})$ seems most effective ${ }^{96}$. Interestingly, no human study found that high frequency $(>100 \mathrm{~Hz})$ stimulation had a detrimental effect on axial motor function, in contrast with the animal studies ${ }^{86}$. Similar improvements are reported with PPN DBS in combination with other targets (caudal Zona incerta, STN, GPi) $)^{97-99}$. The effects of PPN implanted into the right side may have slightly 
better outcome, possibly suggesting the presence of a 'dominant PPN'100. However, the comparative efficacy of unilateral versus bilateral stimulation is far from resolved.

After bilateral PPN stimulation compared with unilateral stimulation, the time spent on a turn task was less, without changes in spatio-temporal measures of gait ${ }^{101}$. Thus, there seems to be a specific effect of PPN DBS on turning and body weight shifting between lower limbs. This notion is consistent with animal studies showing that PPN stimulation mainly affects postural tone while cuneiform nucleus (CNF) stimulation promotes stepping. Accordingly, two case reports found a positive effect of PPN DBS on Pisa syndrome (i.e. a lateral trunk flexion) ${ }^{102,103}$. A clinicopathological study in two patients with progressive supranuclear palsy (hence not idiopathic PD) found that a placement in the PPN adjacent to the CNF produced some clinical benefit on gait initiation ${ }^{104}$.

The mechanism of action of PPN DBS is still far from being elucidated and may be related to an effect on the cholinergic pathways connecting PPN and thalamus and involved in vigilance and sleep/awake cycle. In keeping with this hypothesis, PPN DBS improves reaction times ${ }^{105}$ and attention in $\mathrm{PD}^{103,106}$. Alternative mechanisms engaging local locomotor networks, descending pathways and disrupting pathological cortical and subcortical oscillations with, for example, stimulation spread to the adjacent medial lemniscus or reticular formation also need to be considered. A study using $\left[{ }^{15} \mathrm{O}\right] \mathrm{H}_{2} \mathrm{O} P E T$ in patients with advanced PD showed unilateral PPN DBS increased blood flow in subcortical regions such as the thalamus, cerebellum and midbrain region (including the MLR) as well as different cortical areas involving medial sensorimotor cortex extending into caudal SMA. ${ }^{107}$ Interestingly, improved imagined walking distance after DBS of the subthalamic nucleus in PD patients is related to activity changes in the MLR, as shown by a recent PET study ${ }^{108}$.

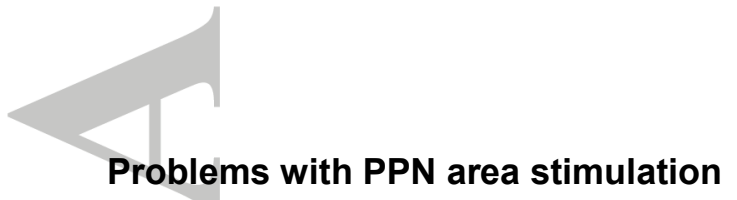


What is the actual outcome of PPN area stimulation? Results to date are unfortunately inconclusive, both for theoretical and for methodological reasons.

\section{Theoretical issues}

It is not clear whether it is actually the PPN that is being stimulated, and, if yes, what area within the PPN. Indeed, the actual location of the PPN in humans remains a matter of debate $^{109-111}$ and its precise delineation is unknown. Consequently, surgical teams have set, and aimed at, different targets ${ }^{94,101,112}$, making it difficult, if not impossible, to conclude on the role of the PPN and to compare outcomes. Inter-individual variability of the brainstem further complicates the matter. As noted above, the PPN has degenerated in $\mathrm{PD}^{113,114}$ with a cell loss correlated with gait disability ${ }^{115}$. Such degeneration of the targeted structure, together with the heterogeneity of its cell population, questions the mechanisms underlying the efficacy of stimulation, or lack thereof.

\section{Practical issues}

Patients under study underwent different surgical procedures from one center to the next, ranging from bilateral PPN area implantation together with STN or caudal Zona Incerta implantation ${ }^{93,97,98,112}$, bilateral PPN area implantation in patients already benefiting from STN stimulation ${ }^{94}$, lone unilateral or bilateral PPN area implantation in patients without previous brain surgery ${ }^{95,105}$. This, together with the uncertainty regarding the structure actually stimulated, makes it difficult to interpret the reported results regarding specific PPN area stimulation effects.

Most studies failed to meet high quality standards, being open label and sometimes missing pre-surgery baseline data altogether. Other confounding factors include small sample sizes, ill-defined inclusion criteria, varied gait disorders, lack of specific gait and FOG assessments, differences in assessment procedures and outcome criteria, and the likely withholding of negative outcomes. Furthermore, unlike that to STN stimulation, the response to PPN area stimulation is slow, taking days to set in. It also wanes very slowly following stimulation 
arrest. The effects also wane under stable stimulation conditions, making it mandatory to frequently adjust parameters settings. Because of these characteristics the widely used acute assessment protocols are inadequate to assess the effects of PPN area stimulation.

Quality of data: Close to one hundred papers have reported on PPN area stimulation in humans, but only 6 studies involved double-blind assessments ${ }^{94-96,101,116,117}$, and one was single-blinded ${ }^{93}$. These studies involved small sample sizes, ranging from one ${ }^{117}$ to 7 patients ${ }^{101}$, as well as variable stimulation periods before assessment (one hour to six weeks). Objective assessment protocols also differed.

Assessment protocols: Methodological flaws and differences also make it difficult to pinpoint the specific effects of PPN area stimulation. Regarding motor assessments, many studies fail to report specific gait evaluation or objective measures of FOG before and after surgery. Often, the UPDRS Activities of Daily Living (II) or Motor section (III) total scores and various combinations of axial and gait scores were the only outcomes. These are not sensitive or specific enough to clarify the effects of PPN area stimulation.

Furthermore, specific gait and FOG assessments lead to inconsistent or even contradictory results. The same is true regarding quantitative gait analysis ${ }^{101,116,118}$. Thus, it is not clear whether PPN area stimulation, when effective, improves gait, $\mathrm{FOG}^{94,96}$ or falls, related ${ }^{94,96}$ or unrelated to $\mathrm{FOG}^{95}$.

Inclusion criteria: Finally, which patients could benefit from PPN area surgery, if any, is not clear either. Well controlled studies showed that chronic outcome is highly variable, ranging from no effect (or even worsening), to mild or major improvement ${ }^{94,95,117}$ in FOG or frequency of falls. Yet, available data provide distressingly little information on the clinical profile of the patients and some studies failed to perform thorough pre-surgery assessments $^{93,105,118}$. In all studies, the phenotype of the patients appears quite variable, especially regarding quality of gait pattern, frequency and characteristics of falls, response to levodopa (both overall and for FOG specifically) and, as already mentioned, the prior brain 
surgery status. Such variability in the characteristics of the patients is likely to influence the outcome of the surgery.

The distinction between levodopa responsive and resistant FOG is an important consideration when evaluating the effect of PPN stimulation. Levodopa responsive FOG generally responds well to treatment of the $\mathrm{STN}^{119,120}$. With advancing disease, FOG becomes levodopa-resistant, probably by progression of non-dopaminergic disease. Whether this is due to cholinergic failure and can be addressed by stimulating the cholinergic part of the PPN, or whether other neurotransmitters such as glutamate play their part, remains to be determined. Future studies need to be clear concerning what phenotype of FOG is included and which phenotype reacts most.

In summary, objective assessments suggest that PPN area stimulation might improve FOG in some patients, without significant effects on other gait parameters. FOG reduction may contribute to explaining a positive outcome on falls. Whether stimulation might also improve postural stability remains to be clarified. Altogether, it will not be possible to conclude on the best indication, if any, of PPN area stimulation until we know better where and how to stimulate, and until controlled studies with thorough inclusion criteria and consistent evaluation protocols are conducted.

\section{Conclusion}

While FOG remains a mysterious phenomenon, animal and imaging studies have started to unravel the mystery. The outcome of these studies point to a dynamic process of hypo and hyperactivation in cortical areas such as the SMA, as well as subcortical areas such as the striatum and the MLR including the PPN. The specific role of the PPN remains unclear. Control of locomotion is very complex. It is a network operation of multiple interacting brain areas (or even brain networks) using multiple neurotransmitters. One way forward may be to look at the entire network instead of one detailed cell group in the network. When doing experiments, one has to be highly specific on the part of locomotion (freezing, posture, 
slowness of gait) that is being studied. Whether different phenomenological subtypes of freezing (akinetic, trembling, responsiveness to environment) have truly a different pathology or are a reflection of a different (extent of) defective node of the network, remains to be determined.

The dopaminergic component is a critical element. If only dopamine depletion is the problem, this will lead to OFF freezing. If then another element (cholinergic, glutamatergic) breaks down, the system breaks down leading to more complex freezing including ON freezing. Too much dopamine will also cause the system to fail because of its $U$-shaped function ${ }^{121}$.

For levodopa responsive FOG, STN stimulation offers opportunities ${ }^{122}$ but for levodopa resistant FOG in PD and other disorders, we are still left to ponder. Although the PPN is embraced as a possible target for FOG, especially for levodopa resistant FOG leading to falls, to date evidence is inconclusive. Further work is needed to investigate where, how and who to stimulate to get good results. Clear patient selection, thorough gait and falls assessment and strict definition of the surgical target will be fundamental for future research. Even then, the compensatory role of PPN area stimulation may be limited by disease progression.

Basic science studies suggest the PPN is most involved in tone and balance, more than in stepping. Consequently and fitting, patient studies hitherto suggest PPN stimulation may improve falls, more than freezing of gait. Giving attention to other possibly relevant areas in the dynamic pathophysiological process of FOG, such as the SMA or the MLR area dorsomedial to the PPN (including the laterodorsal tegmental nucleus) may provide further direction in the development of effective therapies.

\section{Acknowledgements:}

Grant JSPS KAKENHI \#26120004 and \#25290001 to Kaoru Takakusaki. Mark Hallett is supported by the NINDS Intramural Program. Funding by Sartain Lanier Family Foundation and the Curtis Family Foundation for Stewart Factor. We thank Prof Nir Giladi and Prof Jeff 
Hausdorff for stimulating us to write this review after the First International Freezing of Gait Congress in Tel Aviv in 2014.

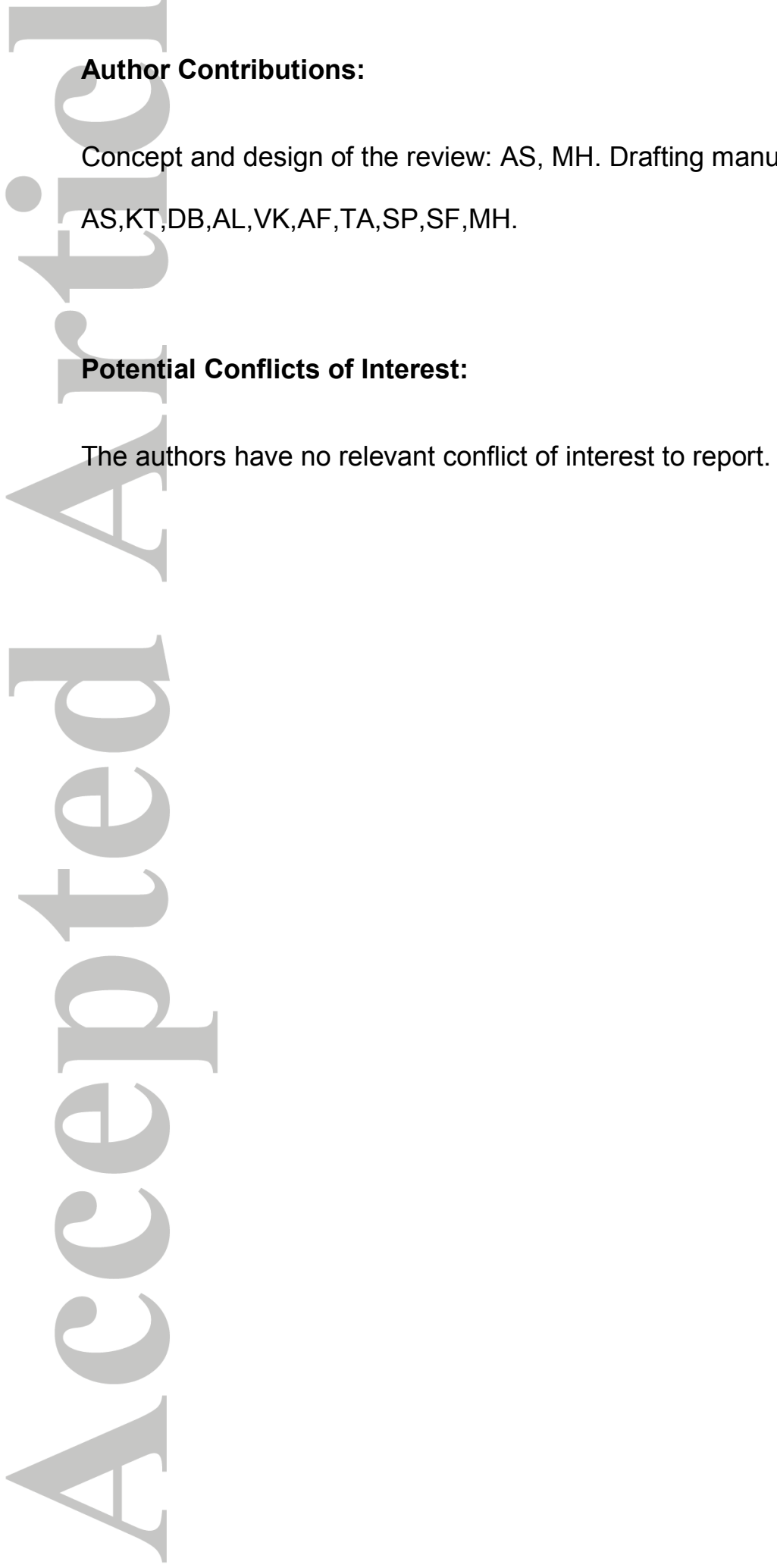


Figure Legends

Figure 1:

Neuronal mechanisms of controlling locomotion

A. Dorsal system for cognitive locomotor control. A visuo-motor pathway from the visual cortex to motor cortex via the parietal cortex contributes to this control. Corticofugal projections act on to the basal ganglia nuclei, brainstem and spinal cord. Dopaminergic (DA) projection from the substantia nigral pars compacta $(\mathrm{SNc})$ to the caudate and putamen $(\mathrm{CPu})$ may be involved in learning the locomotor behaviors. GABAergic output from the basal ganglia nuclei (internal segment of the globus pallidus and substantia nigra pars reticulata; GPi/SNr) acts on MLR/PPN area may control locomotion and posture. Efferents from the midbrain locomotor region (MLR) activate both excitatory system and locomotor pathway. The excitatory system arises from the locus coeruleus (LC) and the raphe nuclei (RN). The locomotor pathway consists of reticulospinal neurons arising from the ventromedial medulla corresponding to the nucleus reticularis magnocellularis (NRMc). Cholinergic and glutamatergic projections from the PPN excite SNC-DA neurons. Cholinergic PPN neurons also excite pontine reticular formation neurons, which, in turn, activate reticulospinal neurons in the medial medulla corresponding to the nucleus reticularis gigantocellularis (NRGc). These descending tracts act on central pattern generator (CPG) in spinal cord to evoke locomotion. Efferents from the cerebellar locomotor region (CLR) may excite locomotor pathway.

B. Ventral system for emotional locomotor control. Efferents from the amygdala (AMD) and hippocampus (Hipp) project to the nucleus accumbens (NAc). GABAergic NAc neurons project to ventral pallidus (VP) and the SNr, which control activity of the MLR/PPN neurons. Efferents from the amygdala and the hippocampus also act on lateral 
hypothalamic area, which corresponds to the subthalamic locomotor region (SLR). DA projections from the ventral tegmental area (VTA) may contribute to the reward-oriented locomotor behaviors. See text for further details.

Abbreviations: E; extensor motoneurons, F; flexor motoneurons.

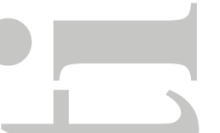

\section{Figure 2:}

Analysis of the evolution of FOG episodes in the MPTP-treated monkey.

$A$ and $B$, recordings of leg movements with an accelerometer placed on the back of the leg during the whole duration of FOG episodes ( 15 s). Each episode ( $A$ and $B$ ) has regular oscillations corresponding to tremor before the end of freezing. The traces show raw accelerometry data. $\mathrm{C}$ and $\mathrm{D}$, rate meters for the whole duration of the FOG episodes corresponding to $\mathrm{A}$ and $\mathrm{B}$, respectively. The peaks correspond to the tremor periods towards the end of the freezing episode when walk restarts and initial oscillatory movements. Rate meters used the data produced after detection of full phase oscillations above the threshold. The graphs were constructed with a bin width of $500 \mathrm{~ms}$, and smoothed using a Gaussian filter. E, distribution of FOG tremor frequencies. The graph shows the frequencies $(\mathrm{Hz})$ found across 20 recordings of tremor, each in a separate FOG episode. The average rate in the recorded tremors was $7.07 \mathrm{~Hz}\left( \pm 1.47\right.$ STD). Taken from ${ }^{50}$ with permission.

\section{Figure 3:}

Dynamic cerebral substrate of FOG, based on data from fMRI studies Snijders et al 2011, Vercruysse et al 2014, Shine et al 2013a and 2013b

During repetitive continuous movement of hands or legs, or motor imagery of gait, cortical activity in areas as the SMA and PFC is reduced, while subcortical activity is increased; for the STN in the hands, in the MLR for leg movents or imagery of gait. During a freezing 
episode, SMA activity is still reduced, but also subcortical areas STN and MLR show reduced activity. In contrast, frontoparietal areas and the insula show increased activity.

Abbreviations: SMA = supplementary motor area; PFC = prefrontal cortex; STN = subthalamic nucleus; MLR = Mesencephalic locomotor region; DLPFC = dorsolateral prefrontal cortex

$r$

\section{Figure 4:}

In normal macaque, multiple sessions of DBS unilateral PPN stimulation at several different frequencies: significant decrease in motor activity with higher frequency DBS (45 to $100 \mathrm{~Hz}$ ).

\section{Figure 5:}

(A) (A) Location of the PPN identified on the ICBM 2009b NLIN T1 asymmetric template by Andreas Horn, Michael D. Fox and Clifford B. Saper, by transferring the location of ChATstaining of neurons in the PPN in human brain ${ }^{123}$ to standard atlas space using neuroanatomical landmarks.

(B) MRI with bilateral electrodes for stimulating the PPN. Note that to implant the PPN region the surgeon has to avoid traversing the lateral ventricles which would increase the risk of hemorrhage. To remain intra-parenchymal the surgeon approaches the target calculating the azimuth and declination to place as many contacts in the PPN area as possible. (Part B courtesy of Dr. Peter Silburn, Brisbane Australia

\section{Supplementary Video 1:}

Monkey with FOG in the hind limbs with many of the characteristics typical of human FOG, including a $4-10 \mathrm{~Hz}$ tremor similar to that seen in patients ${ }^{51}$. 
Table 1. Summary of published clinical studies of PPN DBS for freezing of gait in Parkinson's disease

\begin{tabular}{|c|c|c|c|c|c|c|c|}
\hline $\begin{array}{l}\text { Study } \\
\text { design }\end{array}$ & $\begin{array}{l}\text { Author- } \\
\text { year }\end{array}$ & $\mathbf{N}$ & Type patient & Target & $\begin{array}{l}\text { Stimulation } \\
\text { parameter }\end{array}$ & $\begin{array}{l}\text { Follow-up } \\
\text { in months }\end{array}$ & Outcomes \\
\hline & $\begin{array}{l}\text { Stefani- } \\
2007^{93}\end{array}$ & 6 & $\begin{array}{l}\text { Disabling axial } \\
\text { signs }\end{array}$ & $\begin{array}{l}\text { Bilateral } \\
\text { STN and } \\
\text { PPN }\end{array}$ & $\begin{array}{l}2 \mathrm{~V} \\
60 \mu \mathrm{s} \\
25 \mathrm{~Hz}\end{array}$ & 6 & $\begin{array}{l}\text { Combined therapy } \\
\text { improved axial } \\
\text { motor symptoms. } \\
\text { Efficacy declined } \\
\text { over time. }\end{array}$ \\
\hline & $\begin{array}{l}\text { Ferraye- } \\
2010^{94}\end{array}$ & 6 & $\begin{array}{l}\text { Severe } \\
\text { freezing } \\
\text { unresponsive } \\
\text { to levodopa } \\
\text { and STN DBS }\end{array}$ & $\begin{array}{l}\text { Bilateral } \\
\text { STN and } \\
\text { PPN }\end{array}$ & $\begin{array}{l}1.2-3.8 \mathrm{~V} \\
60-90 \mu \mathrm{s} \\
15-25 \mathrm{~Hz}\end{array}$ & 12 & $\begin{array}{l}\text { Double-blind: no } \\
\text { change. } \\
\text { Improvement in } \\
\text { OFF freezing and } \\
\text { falls. Significant } \\
\text { inter-subjects } \\
\text { variability. }\end{array}$ \\
\hline & $\begin{array}{l}\text { Moro- } \\
2010^{95}\end{array}$ & 6 & $\begin{array}{l}\text { Severe } \\
\text { freezing \& falls } \\
\text { unresponsive } \\
\text { to medical } \\
\text { treatment }\end{array}$ & $\begin{array}{l}\text { Unilateral } \\
\text { PPN }\end{array}$ & $\begin{array}{l}2 \mathrm{~V} \\
70 \mu \mathrm{s} \\
67 \mathrm{~Hz}\end{array}$ & 12 & $\begin{array}{l}\text { No overall } \\
\text { improvement. } \\
\text { Improvement in ON } \\
\text { \& OFF falls. } \\
\text { Post-hoc: slightly } \\
\text { better right PPN }{ }^{100}\end{array}$ \\
\hline & $\begin{array}{l}\text { Khan- } \\
2011^{98}\end{array}$ & 7 & $\begin{array}{l}\text { Freezing \& } \\
\text { falls } \\
\text { unresponsive } \\
\text { to levodopa }\end{array}$ & $\begin{array}{l}\text { Bilateral } \\
\text { PPN \& Zona } \\
\text { Incerta }\end{array}$ & $\begin{array}{l}2.6 \mathrm{~V} \\
60 \mu \mathrm{s} \\
60 \mathrm{~Hz}\end{array}$ & 13 & $\begin{array}{l}\text { Improved axial } \\
\text { UPDRS-III } \\
\text { subscore in OFF } \\
\text { state. Synergic } \\
\text { effect between Zi } \\
\text { and PPN } \\
\text { stimulation. }\end{array}$ \\
\hline & $\begin{array}{l}\text { Khan- } \\
2012^{97}\end{array}$ & 5 & $\begin{array}{l}\text { Freezing \& } \\
\text { falls } \\
\text { unresponsive } \\
\text { to levodopa }\end{array}$ & $\begin{array}{l}\text { Unilateral } \\
\text { and Bilateral } \\
\text { PPN \& Zona } \\
\text { Incerta }\end{array}$ & & $27.0 \pm 19.6$ & $\begin{array}{l}\text { Improved axial } \\
\text { UPDRS-III } \\
\text { subscore in ON } \\
\text { state with bilateral }\end{array}$ \\
\hline
\end{tabular}




\begin{tabular}{|c|c|c|c|c|c|c|c|}
\hline 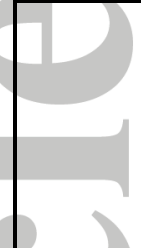 & & & & & & & $\begin{array}{l}\text { PPN stimulation. } \\
\text { Synergic effect of } \\
\text { PPN with Zi } \\
\text { stimulation. }\end{array}$ \\
\hline & $\begin{array}{l}\text { Nosko- } \\
2015^{96}\end{array}$ & 9 & $\begin{array}{l}\text { Severe gait } \\
\text { disorders \& } \\
\text { freezing }\end{array}$ & $\begin{array}{l}\text { Bilateral } \\
\text { PPN \& STN }\end{array}$ & $\begin{array}{l}0.8-2.6 \mathrm{~V} \\
60 \mu \mathrm{s} \\
10-25 \mathrm{~Hz}\end{array}$ & 12 & $\begin{array}{l}\text { Lower frequency } \\
\text { more efficacious } \\
\text { than high } \\
\text { frequency. }\end{array}$ \\
\hline & $\begin{array}{l}\text { Thevatha } \\
\text { san-2010 } \\
105\end{array}$ & 11 & $\begin{array}{l}\text { Severe } \\
\text { freezing \& falls } \\
\text { unresponsive } \\
\text { to medical } \\
\text { treatment }\end{array}$ & $\begin{array}{l}\text { Bilateral } \\
\text { PPN, also } \\
\text { Zona Incerta } \\
\text { in } 3 \text { patients }\end{array}$ & $\begin{array}{l}2-3.7 \mathrm{~V} \\
60 \mu \mathrm{s} \\
20-35 \mathrm{~Hz}\end{array}$ & $12.7 \pm 12.1$ & $\begin{array}{l}\text { Speed of reaction } \\
\text { improved by } \\
\text { stimulation. }\end{array}$ \\
\hline & $\begin{array}{l}\text { Thevatha } \\
\text { san-2011 } \\
124\end{array}$ & 8 & $\begin{array}{l}\text { Severe } \\
\text { freezing }\end{array}$ & $\begin{array}{l}\text { Bilateral } \\
\text { PPN }\end{array}$ & $\begin{array}{l}2.5-4.3 \mathrm{~V} \\
60 \mu \mathrm{s} \\
30-35 \mathrm{~Hz}\end{array}$ & $19.7 \pm 9.2$ & $\begin{array}{l}\text { PPN DBS restores } \\
\text { proximal StatReact } \\
\text { and reaction time }\end{array}$ \\
\hline , & $\begin{array}{l}\text { Thevatha } \\
\text { san-2012 } \\
76\end{array}$ & 7 & $\begin{array}{l}\text { Severe } \\
\text { freezing }\end{array}$ & $\begin{array}{l}\text { Bilateral } \\
\text { PPN }\end{array}$ & $\begin{array}{l}2.2-4.3 \mathrm{~V} \\
60 \mu \mathrm{s} \\
35 \mathrm{~Hz}\end{array}$ & $<2.5$ & $\begin{array}{l}\text { Freezing improved } \\
\text { with mere electrode } \\
\text { insertion. Alpha } \\
\text { oscillations caudal } \\
\text { PPN correlate with } \\
\text { gait function }\end{array}$ \\
\hline & $\begin{array}{l}\text { Mazzone } \\
-2011^{116}\end{array}$ & 23 & Freezing & $\begin{array}{l}\text { Unilateral } \\
\text { PPN }\end{array}$ & & $21.3 \pm 10.0$ & $\begin{array}{l}\text { DBS improved both } \\
\text { UPDRS-III and the } \\
\text { axial subscores }\end{array}$ \\
\hline & $\begin{array}{l}\text { Mazzone } \\
-2014^{125}\end{array}$ & 10 & $\begin{array}{l}\text { Drug resistant } \\
\text { gait disabilities }\end{array}$ & $\begin{array}{l}\text { Unilateral } \\
\text { PPN }\end{array}$ & $\begin{array}{l}2.5-3 \mathrm{~V} \\
60 \mu \mathrm{s} \\
40 \mathrm{~Hz}\end{array}$ & 12 & $\begin{array}{l}\text { DBS improved } \\
\text { some parameters } \\
\text { of gait analysis }\end{array}$ \\
\hline
\end{tabular}




\section{References:}

1. Giladi N. Freezing of gait. Clinical overview. Adv Neurol. 2001;87:191-7.

2. Walton CC, Shine JM, Hall JM, et al. The major impact of freezing of gait on quality of life in Parkinson's disease. Journal of neurology. 2015 Jan;262(1):108-15.

3. Giladi N, Nieuwboer A. Understanding and treating freezing of gait in parkinsonism, proposed working definition, and setting the stage. Mov Disord. 2008;23 Suppl 2:S423-5.

4. Schaafsma JD, Balash Y, Gurevich T, Bartels AL, Hausdorff JM, Giladi N. Characterization of freezing of gait subtypes and the response of each to levodopa in Parkinson's disease. European journal of neurology. 2003 Jul;10(4):391-8.

5. Espay AJ, Fasano A, van Nuenen BF, Payne MM, Snijders AH, Bloem BR. "On" state freezing of gait in Parkinson disease: a paradoxical levodopa-induced complication. Neurology. 2012 Feb $14 ; 78(7): 454-7$.

6. Snijders AH, van de Warrenburg BP, Giladi N, Bloem BR. Neurological gait disorders in elderly people: clinical approach and classification. Lancet Neurol. 2007;6(1):63-74.

7. Woollacott M, Shumway-Cook A. Attention and the control of posture and gait: a review of an emerging area of research. GaitPosture. 2002;16(1):1-14.

8. Morton SM, Bastian AJ. Cerebellar control of balance and locomotion. Neuroscientist. 2004;10:247-59.

9. Hinsey JC, Ranson SW, McNattin FR. The role of the hypothalamus and mesencephalon in locomotion. Arch Neurol Psychiatry. 1930(23):1-43.

10. Mori S. Integration of posture and locomotion in acute decerebrate cats and in awake, freely moving cats. ProgNeurobiol. 1987;28(2):161-95.

11. Shik ML, Orlovsky GN. Neurophysiology of locomotor automatism. Physiol Rev. $1976 ; 56(3): 465-501$.

12. Brooks VB, Stoney SD, Jr. Motor mechanisms: the role of the pyramidal system in motor control. AnnuRevPhysiol. 1971;33:337-92. 
13. Yakovenko S, Drew T. A motor cortical contribution to the anticipatory postural adjustments that precede reaching in the cat. Journal of neurophysiology. 2009 Aug;102(2):853-74.

14. Marigold DS, Drew T. Contribution of cells in the posterior parietal cortex to the planning of visually guided locomotion in the cat: effects of temporary visual interruption. JNeurophysiol.

\section{1;105(5):2457-70.}

15. Nakajima K, Mori F, Tachibana A, Nambu A, Mori S. Cortical Mechanisms for the control of bipedal locomotion in Japanese monkeys: I. Local inactivation of the primary motor cortex (M1). Neurosci Res. 2003;46(Suppl 1):S156.

16. Mori F, Nakajima K, Tachibana A. Cortical mechanisms for the control of bipedal locomotion in Japanese monkeys: II. Local inactivation of the supplementary motor area (SMA). Neurosci Res. 2003;46(Suppl 1):S157.

17. Keizer K, Kuypers HG. Distribution of corticospinal neurons with collaterals to the lower brain stem reticular formation in monkey (Macaca fascicularis). Experimental brain research. $1989 ; 74(2): 311-8$.

18. Matsuyama K, Drew T. Organization of the projections from the pericruciate cortex to the pontomedullary brainstem of the cat: a study using the anterograde tracer Phaseolus vulgarisleucoagglutinin. JComp Neurol. 1997;389(4):617-41.

19. Aravamuthan BR, McNab JA, Miller KL, et al. Cortical and subcortical connections within the pedunculopontine nucleus of the primate Macaca mulatta determined using probabilistic diffusion tractography. JClinNeurosci. 2009;16(3):413-20.

20. Mori S, Matsui T, Kuze B, Asanome M, Nakajima K, Matsuyama K. Stimulation of a restricted region in the midline cerebellar white matter evokes coordinated quadrupedal locomotion in the decerebrate cat. JNeurophysiol. 1999;82(1):290-300.

21. Grillner S, Georgopoulos AP, Jordan LM. Selection and initiation of motor behavior. In: Stein PSG, editor. Neurons, Networks, and Motor Behavior. Cambridge, MA: MIT Press; 1997. p. 3-19. 
22. Sherman D, Fuller PM, Marcus J, et al. Anatomical Location of the Mesencephalic Locomotor Region and Its Possible Role in Locomotion, Posture, Cataplexy, and Parkinsonism. Frontiers in neurology. 2015;6:140.

23. Alam M, Schwabe K, Krauss JK. The pedunculopontine nucleus area: critical evaluation of interspecies differences relevant for its use as a target for deep brain stimulation. Brain. 2011 Jan;134(Pt 1):11-23.

24. Takakusaki K, Chiba R, Nozu T, Okumura T. Brainstem control of locomotion and muscle tone with special reference to the role of the mesopontine tegmentum and medullary reticulospinal systems. J Neural Transm (Vienna). 2015 Oct 26.

25. Petzold A, Valencia M, Pal B, Mena-Segovia J. Decoding brain state transitions in the pedunculopontine nucleus: cooperative phasic and tonic mechanisms. Front Neural Circuits. 2015;9:68.

26. Takakusaki K, Habaguchi T, Ohtinata-Sugimoto J, Saitoh K, Sakamoto T. Basal ganglia efferents to the brainstem centers controlling postural muscle tone and locomotion: a new concept for understanding motor disorders in basal ganglia dysfunction. Neuroscience. 2003;119(1):293-308. 27. Takakusaki K, Habaguchi T, Saitoh K, Kohyama J. Changes in the excitability of hindlimb motoneurons during muscular atonia induced by stimulating the pedunculopontine tegmental nucleus in cats. Neuroscience. 2004;124(2):467-80.

28. Takakusaki K, Oohinata-Sugimoto J, Saitoh K, Habaguchi T. Role of basal ganglia-brainstem systems in the control of postural muscle tone and locomotion. ProgBrain Res. 2004;143:231-7. 29. Takakusaki K, Takahashi K, Saitoh K, et al. Orexinergic projections to the cat midbrain mediate alternation of emotional behavioural states from locomotion to cataplexy. JPhysiol. 2005;568(Pt 3):1003-20.

30. Takakusaki K, Obara K, Nozu T, Okumura T. Modulatory effects of the GABAergic basal ganglia neurons on the PPN and the muscle tone inhibitory system in cats. Arch ItalBiol. 2011;149(4):385-405. 
31. Armstrong DM. Supraspinal contributions to the initiation and control of locomotion in the cat. ProgNeurobiol. 1986;26(4):273-361.

32. Garcia-Rill E, Houser CR, Skinner RD, Smith W, Woodward DJ. Locomotion-inducing sites in the vicinity of the pedunculopontine nucleus. Brain ResBull. 1987;18(6):731-8.

33. Mori S, Matsui T, Kuze B, Asanome M, Nakajima K, Matsuyama K. Cerebellar-induced locomotion: reticulospinal control of spinal rhythm generating mechanism in cats. AnnNYAcadSci. 1998;860:94-105.

34. Fung SJ, Barnes CD. Evidence of facilitatory coerulospinal action in lumbar motoneurons of cats. Brain Res. 1981;216(2):299-311.

35. Mori S, Kawahara K, Sakamoto T, Aoki M, Tomiyama T. Setting and resetting of level of postural muscle tone in decerebrate cat by stimulation of brain stem. JNeurophysiol. 1982;48(3):737-

48.

36. Sakai M, Matsunaga M, Kubota A, Yamanishi Y, Nishizawa Y. Reduction in excessive muscle tone by selective depletion of serotonin in intercollicularly decerebrated rats. Brain Res. 2000;860(12):104-11.

37. DeLong MR, Wichmann T. Circuits and circuit disorders of the basal ganglia. ArchNeurol. 2007;64(1):20-4.

38. Takakusaki K, Tomita N, Yano M. Substrates for normal gait and pathophysiology of gait disturbances with respect to the basal ganglia dysfunction. JNeurol. 2008;255 Suppl 4:19-29.

39. Slawinska U, Kasicki S. Theta-like rhythm in depth EEG activity of hypothalamic areas during spontaneous or electrically induced locomotion in the rat. Brain Res. 1995 Apr 24;678(1-2):117-26.

40. Swanson LW, Mogenson GJ. Neural mechanisms for the functional coupling of autonomic, endocrine and somatomotor responses in adaptive behavior. Brain Res. 1981 Aug;228(1):1-34. 41. Lynd-Balta E, Haber SN. Primate striatonigral projections: a comparison of the sensorimotorrelated striatum and the ventral striatum. JComp Neurol. 1994;345(4):562-78. 
42. Stephenson-Jones M, Ericsson J, Robertson B, Grillner S. Evolution of the basal ganglia: dualoutput pathways conserved throughout vertebrate phylogeny. J Comp Neurol. 2012 Sep 1;520(13):2957-73.

43. Matsumura M, Nambu A, Yamaji Y, et al. Organization of somatic motor inputs from the frontal lobe to the pedunculopontine tegmental nucleus in the macaque monkey. Neuroscience. 2000;98(1):97-110.

44. Jacobs JV, Lou JS, Kraakevik JA, Horak FB. The supplementary motor area contributes to the timing of the anticipatory postural adjustment during step initiation in participants with and without Parkinson's disease. Neuroscience. 2009;164(2):877-85.

45. Marsden CD. Primate models of neurological disorders. Introduction. Adv Neurol. 1975;10:34. 46. Langston JW, Ballard P, Tetrud JW, Irwin I. Chronic Parkinsonism in humans due to a product of meperidine-analog synthesis. Science. 1983;219(4587):979-80.

47. Langston JW, Forno LS, Tetrud J, Reeves AG, Kaplan JA, Karluk D. Evidence of active nerve cell degeneration in the substantia nigra of humans years after 1-methyl-4-phenyl-1,2,3,6-

tetrahydropyridine exposure. AnnNeurol. 1999;46(4):598-605.

48. Burns RS, Chiueh CC, Markey SP, Ebert MH, Jacobowitz DM, Kopin IJ. A primate model of parkinsonism: selective destruction of dopaminergic neurons in the pars compacta of the substantia nigra by N-methyl-4-phenyl-1,2,3,6-tetrahydropyridine. ProcNatlAcadSciUSA. 1983;80(14):4546-50.

49. Ballard PA, Tetrud JW, Langston JW. Permanent human parkinsonism due to 1-methyl-4phenyl-1,2,3,6-tetrahydropyridine (MPTP): seven cases. Neurology. 1985;35(7):949-56.

50. Revuelta GJ, Uthayathas S, Wahlquist AE, Factor SA, Papa SM. Non-human primate FOG develops with advanced parkinsonism induced by MPTP Treatment. Exp Neurol. 2012;237(2):464-9. 51. Moore ST, MacDougall HG, Ondo WG. Ambulatory monitoring of freezing of gait in Parkinson's disease. J Neurosci Methods. 2008 Jan 30;167(2):340-8. 
52. Forno LS, Langston JW, DeLanney LE, Irwin I, Ricaurte GA. Locus ceruleus lesions and eosinophilic inclusions in MPTP-treated monkeys. AnnNeurol. 1986;20(4):449-55.

53. Karachi C, Grabli D, Bernard FA, et al. Cholinergic mesencephalic neurons are involved in gait and postural disorders in Parkinson disease. The Journal of clinical investigation. 2010

\section{Aug;120(8):2745-54.}

54. Grabli D, Karachi C, Folgoas E, et al. Gait disorders in parkinsonian monkeys with pedunculopontine nucleus lesions: a tale of two systems. The Journal of neuroscience : the official journal of the Society for Neuroscience. 2013 Jul 17;33(29):11986-93.

55. Kucinski A, Paolone G, Bradshaw M, Albin RL, Sarter M. Modeling fall propensity in

Parkinson's disease: deficits in the attentional control of complex movements in rats with corticalcholinergic and striatal-dopaminergic deafferentation. The Journal of neuroscience : the official journal of the Society for Neuroscience. 2013 Oct 16;33(42):16522-39.

56. Kucinski A, Albin RL, Lustig C, Sarter M. Modeling falls in Parkinson's disease: Slow gait, freezing episodes and falls in rats with extensive striatal dopamine loss. Behavioural brain research. 2015 Apr 1;282:155-64.

57. Gut NK, Winn P. Deep brain stimulation of different pedunculopontine targets in a novel rodent model of parkinsonism. The Journal of neuroscience : the official journal of the Society for Neuroscience. 2015 Mar 25;35(12):4792-803.

58. Roseberry TK, Lee AM, Lalive AL, Wilbrecht L, Bonci A, Kreitzer AC. Cell-Type-Specific Control of Brainstem Locomotor Circuits by Basal Ganglia. Cell. 2016 Jan 28;164(3):526-37.

59. Bouvier J, Caggiano V, Leiras R, et al. Descending Command Neurons in the Brainstem that Halt Locomotion. Cell. 2015 Nov 19;163(5):1191-203.

60. Hasselmo ME, Sarter M. Modes and models of forebrain cholinergic neuromodulation of cognition. Neuropsychopharmacology : official publication of the American College of

Neuropsychopharmacology. 2011 Jan;36(1):52-73. 
61. Semba K, Fibiger HC. Afferent connections of the laterodorsal and the pedunculopontine tegmental nuclei in the rat: a retro- and antero-grade transport and immunohistochemical study. J

Comp Neurol. 1992 Sep 15;323(3):387-410.

62. Bohnen NI, Kaufer DI, Ivanco LS, et al. Cortical cholinergic function is more severely affected in parkinsonian dementia than in Alzheimer disease: an in vivo positron emission tomographic study. Archives of neurology. 2003 Dec;60(12):1745-8.

63. Bohnen NI, Muller ML, Kotagal V, et al. Heterogeneity of cholinergic denervation in Parkinson's disease without dementia. Journal of cerebral blood flow and metabolism : official journal of the International Society of Cerebral Blood Flow and Metabolism. 2012 Aug;32(8):1609-17. 64. Muller ML, Bohnen NI. Cholinergic dysfunction in Parkinson's disease. Current neurology and neuroscience reports. 2013 Sep;13(9):377.

65. Snijders AH, Leunissen I, Bakker M, et al. Gait-related cerebral alterations in patients with Parkinson's disease with freezing of gait. Brain. 2011;134:59-72.

66. Peterson DS, Pickett KA, Duncan R, Perlmutter J, Earhart GM. Gait-related brain activity in people with Parkinson disease with freezing of gait. PloS one. 2014;9(3):e90634.

67. Vercruysse S, Spildooren J, Heremans E, et al. The neural correlates of upper limb motor blocks in Parkinson's disease and their relation to freezing of gait. Cerebral cortex. 2014 Dec;24(12):3154-66.

68. Nieuwboer A, Vercruysse S, Feys P, Levin O, Spildooren J, Swinnen S. Upper limb movement interruptions are correlated to freezing of gait in Parkinson's disease. EurJNeurosci. 2009;29(7):142230.

69. Vercruysse S, Gilat M, Shine JM, Heremans E, Lewis S, Nieuwboer A. Freezing beyond gait in Parkinson's disease: a review of current neurobehavioral evidence. Neuroscience and biobehavioral reviews. 2014 Jun;43:213-27. 
70. Shine JM, Matar E, Ward PB, et al. Differential neural activation patterns in patients with Parkinson's disease and freezing of gait in response to concurrent cognitive and motor load. PloS one. 2013;8(1):e52602.

71. Shine JM, Matar E, Ward PB, et al. Exploring the cortical and subcortical functional magnetic resonance imaging changes associated with freezing in Parkinson's disease. Brain. 2013 Apr;136(Pt 4):1204-15.

72. Hagen YJ, Snijders AH, Munneke M, Duysens J, Bloem BR. Rapid axial turns: the best way to provoke freezing of gait in Parkinson's disease. Parkinsonism Relat Disord. 2008;14:S26.

73. Fling BW, Cohen RG, Mancini M, et al. Functional reorganization of the locomotor network in Parkinson patients with freezing of gait. PloS one. 2014;9(6):e100291.

74. Androulidakis AG, Mazzone P, Litvak V, et al. Oscillatory activity in the pedunculopontine area of patients with Parkinson's disease. Exp Neurol. 2008 May;211(1):59-66.

75. Weinberger M, Hamani C, Hutchison WD, Moro E, Lozano AM, Dostrovsky JO. Pedunculopontine nucleus microelectrode recordings in movement disorder patients. Experimental brain research. 2008 Jun;188(2):165-74.

76. Thevathasan W, Pogosyan A, Hyam JA, et al. Alpha oscillations in the pedunculopontine nucleus correlate with gait performance in parkinsonism. Brain. 2012;135(Pt 1):148-60.

77. Tsang EW, Hamani C, Moro E, et al. Involvement of the human pedunculopontine nucleus region in voluntary movements. Neurology. 2010 Sep 14;75(11):950-9.

78. Fraix V, Bastin J, David O, et al. Pedunculopontine nucleus area oscillations during stance, stepping and freezing in Parkinson's disease. PloS one. 2013;8(12):e83919.

79. Tattersall TL, Stratton PG, Coyne TJ, et al. Imagined gait modulates neuronal network dynamics in the human pedunculopontine nucleus. Nature neuroscience. 2014 Mar;17(3):449-54. 80. Lau B, Welter ML, Belaid $\mathrm{H}$, et al. The integrative role of the pedunculopontine nucleus in human gait. Brain. 2015;138(Pt 5):1284-96. 
81. Jenkinson N, Nandi D, Muthusamy K, et al. Anatomy, physiology, and pathophysiology of the pedunculopontine nucleus. Mov Disord. 2009;24(3):319-28.

82. Zweig RM, Whitehouse PJ, Casanova MF, Walker LC, Jankel WR, Price DL. Loss of pedunculopontine neurons in progressive supranuclear palsy. Annals of neurology. 1987 Jul;22(1):18-

\section{5.}

83. Zweig RM, Jankel WR, Hedreen JC, Mayeux R, Price DL. The pedunculopontine nucleus in Parkinson's disease. AnnNeurol. 1989;26(1):41-6.

84. Aziz TZ, Davies L, Stein J, France S. The role of descending basal ganglia connections to the brain stem in parkinsonian akinesia. BrJNeurosurg. 1998;12(3):245-9.

85. Munro-Davies LE, Winter J, Aziz TZ, Stein JF. The role of the pedunculopontine region in basal-ganglia mechanisms of akinesia. ExpBrain Res. 1999;129(4):511-7.

86. Pereira EA, Nandi D, Jenkinson N, Stein JF, Green AL, Aziz TZ. Pedunculopontine stimulation from primate to patient. JNeural Transm. 2011;118(10):1453-60.

87. Nandi D, Liu X, Winter JL, Aziz TZ, Stein JF. Deep brain stimulation of the pedunculopontine region in the normal non-human primate. JClinNeurosci. 2002;9(2):170-4.

88. Nandi D, Aziz TZ, Giladi N, Winter J, Stein JF. Reversal of akinesia in experimental parkinsonism by GABA antagonist microinjections in the pedunculopontine nucleus. Brain. 2002;125(Pt 11):2418-30.

89. Jenkinson N, Nandi D, Aziz TZ, Stein JF. Pedunculopontine nucleus: a new target for deep brain stimulation for akinesia. Neuroreport. 2005;16(17):1875-6.

90. Jenkinson N, Nandi D, Miall RC, Stein JF, Aziz TZ. Pedunculopontine nucleus stimulation improves akinesia in a Parkinsonian monkey. Neuroreport. 2004;15(17):2621-4.

91. Jenkinson N, Nandi D, Oram R, Stein JF, Aziz TZ. Pedunculopontine nucleus electric stimulation alleviates akinesia independently of dopaminergic mechanisms. Neuroreport. 2006;17(6):639-41. 
92. Mazzone P, Sposato S, Insola A, Scarnati E. The deep brain stimulation of the pedunculopontine tegmental nucleus: towards a new stereotactic neurosurgery. Journal of neural transmission. 2011 Oct;118(10):1431-51.

93. Stefani A, Lozano AM, Peppe A, et al. Bilateral deep brain stimulation of the pedunculopontine and subthalamic nuclei in severe Parkinson's disease. Brain. 2007;130(Pt 6):1596607.

94. Ferraye MU, Debu B, Fraix V, et al. Effects of pedunculopontine nucleus area stimulation on gait disorders in Parkinson's disease. Brain. 2010;133(Pt 1):205-14.

95. Moro E, Hamani C, Poon YY, et al. Unilateral pedunculopontine stimulation improves falls in Parkinson's disease. Brain. 2010;133(Pt 1):215-24.

96. Nosko D, Ferraye MU, Fraix V, et al. Low-frequency versus high-frequency stimulation of the pedunculopontine nucleus area in Parkinson's disease: a randomised controlled trial.

JNeurolNeurosurgPsychiatry. 2015;86(6):674-9.

97. Khan S, Javed S, Mooney L, et al. Clinical outcomes from bilateral versus unilateral stimulation of the pedunculopontine nucleus with and without concomitant caudal zona incerta region stimulation in Parkinson's disease. British journal of neurosurgery. 2012 Oct;26(5):722-5. 98. Khan S, Mooney L, Plaha P, et al. Outcomes from stimulation of the caudal zona incerta and pedunculopontine nucleus in patients with Parkinson's disease. BrJNeurosurg. 2011;25(2):273-80.

99. Schrader C, Seehaus F, Capelle HH, Windhagen A, Windhagen H, Krauss JK. Effects of pedunculopontine area and pallidal DBS on gait ignition in Parkinson's disease. Brain stimulation. 2013 Nov;6(6):856-9.

100. Lam S, Moro E, Poon YY, Lozano AM, Fasano A. Does dominant pedunculopontine nucleus exist? Brain. 2015 Feb;138(Pt 2):e323.

101. Thevathasan W, Cole MH, Graepel CL, et al. A spatiotemporal analysis of gait freezing and the impact of pedunculopontine nucleus stimulation. Brain. 2012;135(Pt 5):1446-54. 
102. Shih LC, Vanderhorst VG, Lozano AM, Hamani C, Moro E. Improvement of pisa syndrome with contralateral pedunculopontine stimulation. Mov Disord. 2013;28(4):555-6.

103. Ricciardi L, Piano C, Bentivoglio AR, Fasano A. Long-term effects of pedunculopontine nucleus stimulation for Pisa syndrome. Parkinsonism Relat Disord. 2014 Dec;20(12):1445-6.

104. Hazrati LN, Wong JC, Hamani C, et al. Clinicopathological study in progressive supranuclear palsy with pedunculopontine stimulation. Mov Disord. 2012;27(10):1304-7.

105. Thevathasan W, Silburn PA, Brooker H, et al. The impact of low-frequency stimulation of the pedunculopontine nucleus region on reaction time in parkinsonism. JNeurolNeurosurgPsychiatry. 2010;81(10):1099-104.

106. Fischer J, Schwiecker K, Bittner V, et al. Modulation of attentional processing by deep brain stimulation of the pedunculopontine nucleus region in patients with parkinsonian disorders. Neuropsychology. 2015 Jul;29(4):632-7.

107. Ballanger B, Lozano AM, Moro E, et al. Cerebral blood flow changes induced by pedunculopontine nucleus stimulation in patients with advanced Parkinson's disease: A [(15)O] H(2)O PET study. HumBrain Mapp. 2009;30(12):3901-9.

108. Weiss PH, Herzog J, Potter-Nerger M, et al. Subthalamic nucleus stimulation improves Parkinsonian gait via brainstem locomotor centers. Mov Disord. 2015 Jul;30(8):1121-5.

109. Yelnik J. PPN or PPD, what is the target for deep brain stimulation in Parkinson's disease? Brain. 2007 Sep;130(Pt 9):e79; author reply e80.

110. Zrinzo L, Zrinzo L, Hariz M. The peripeduncular nucleus: a novel target for deep brain stimulation? Neuroreport. 2007 Oct 8;18(15):1631-2; author reply 2-3.

111. Zrinzo L, Zrinzo LV, Tisch S, et al. Stereotactic localization of the human pedunculopontine nucleus: atlas-based coordinates and validation of a magnetic resonance imaging protocol for direct localization. Brain. 2008;131(Pt 6):1588-98.

112. Mazzone P, Lozano A, Stanzione $P$, et al. Implantation of human pedunculopontine nucleus: a safe and clinically relevant target in Parkinson's disease. Neuroreport. 2005;16(17):1877-81. 
113. Hirsch EC, Graybiel AM, Duyckaerts C, Javoy-Agid F. Neuronal loss in the pedunculopontine tegmental nucleus in Parkinson disease and in progressive supranuclear palsy. Proceedings of the National Academy of Sciences of the United States of America. 1987 Aug;84(16):5976-80.

114. Jellinger K. The pedunculopontine nucleus in Parkinson's disease, progressive supranuclear palsy and Alzheimer's disease. Journal of neurology, neurosurgery, and psychiatry. 1988 Apr;51(4):540-3.

115. Jellinger KA. Post mortem studies in Parkinson's disease--is it possible to detect brain areas for specific symptoms? Journal of neural transmission Supplementum. 1999;56:1-29.

116. Caliandro P, Insola A, Scarnati E, et al. Effects of unilateral pedunculopontine stimulation on electromyographic activation patterns during gait in individual patients with Parkinson's disease. JNeural Transm. 2011;118(10):1477-86.

117. Ostrem JL, Christine CW, Glass GA, Schrock LE, Starr PA. Pedunculopontine nucleus deep brain stimulation in a patient with primary progressive freezing gait disorder.

StereotactFunctNeurosurg. 2010;88(1):51-5.

118. Peppe A, Pierantozzi M, Chiavalon C, et al. Deep brain stimulation of the pedunculopontine tegmentum and subthalamic nucleus: effects on gait in Parkinson's disease. GaitPosture. $2010 ; 32(4): 512-8$.

119. Davis JT, Lyons KE, Pahwa R. Freezing of gait after bilateral subthalamic nucleus stimulation for Parkinson's disease. Clin Neurol Neurosurg. 2006 Jul;108(5):461-4.

120. Nonnekes J, Snijders AH, Nutt JG, Deuschl G, Giladi N, Bloem BR. Freezing of gait: a practical approach to management. Lancet Neurol. 2015 Jul;14(7):768-78.

121. Cools R, D'Esposito M. Inverted-U-shaped dopamine actions on human working memory and cognitive control. Biological psychiatry. 2011 Jun 15;69(12):e113-25.

122. Vercruysse S, Vandenberghe W, Munks L, Nuttin B, Devos H, Nieuwboer A. Effects of deep brain stimulation of the subthalamic nucleus on freezing of gait in Parkinson's disease: a prospective controlled study. Journal of neurology, neurosurgery, and psychiatry. 2014 Aug;85(8):871-7. 
123. Mesulam MM, Geula C, Bothwell MA, Hersh LB.. Human reticular formation: cholinergic neurons of the pedunculopontine and laterodorsal tegmental nuclei and some cytochemical comparisons to forebrain cholinergic neurons. J Comp Neurol 1989 May 22;283(4):611-33.

124. Thevathasan W, Coyne TJ, Hyam JA, et al. Pedunculopontine nucleus stimulation improves gait freezing in Parkinson disease. Neurosurgery. 2011;69(6):1248-53.

125. Mazzone P, Paoloni M, Mangone M, et al. Unilateral deep brain stimulation of the pedunculopontine tegmental nucleus in idiopathic Parkinson's disease: effects on gait initiation and performance. Gait \& posture. 2014 Jul;40(3):357-62.
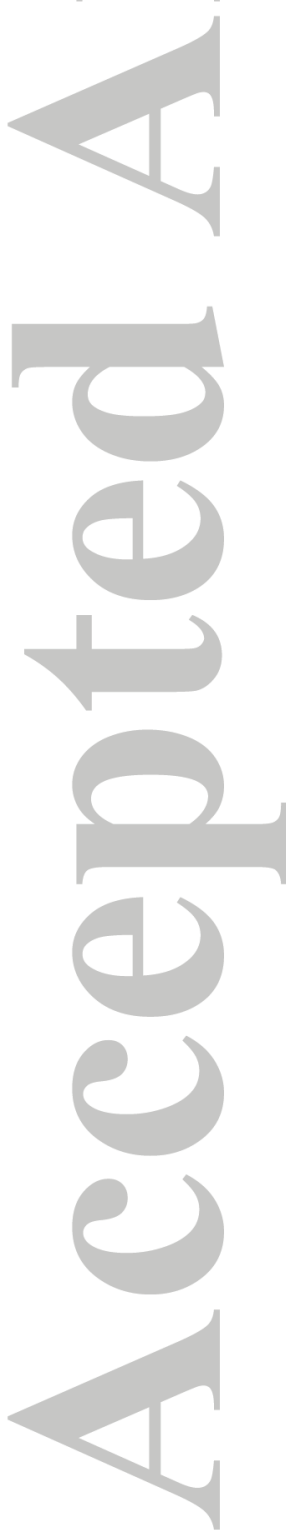


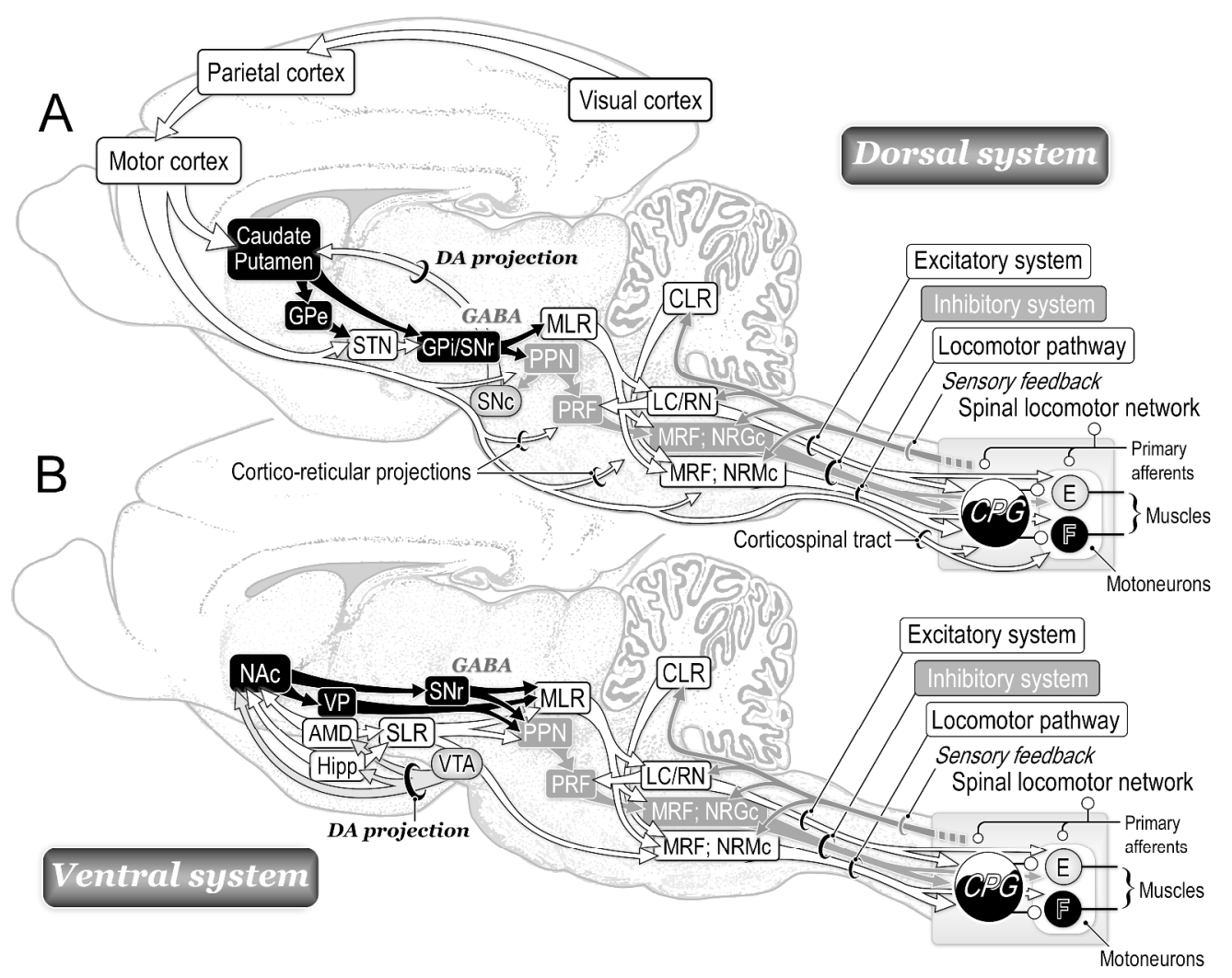

Figure 1:

Neuronal mechanisms of controlling locomotion

A. Dorsal system for cognitive locomotor control. A visuo-motor pathway from the visual cortex to motor cortex via the parietal cortex contributes to this control. Corticofugal projections act on to the basal ganglia nuclei, brainstem and spinal cord. Dopaminergic (DA) projection from the substantia nigral pars compacta $(\mathrm{SNc})$ to the caudate and putamen ( $\mathrm{CPu}$ ) may be involved in learning the locomotor behaviors. GABAergic output from the basal ganglia nuclei (internal segment of the globus pallidus and substantia nigra pars reticulata; GPi/SNr) acts on MLR/PPN area may control locomotion and posture. Efferents from the midbrain locomotor region (MLR) activate both excitatory system and locomotor pathway. The excitatory system arises from the locus coeruleus (LC) and the raphe nuclei (RN). The locomotor pathway consists of reticulospinal neurons arising from the ventromedial medulla corresponding to the nucleus reticularis magnocellularis (NRMc). Cholinergic and glutamatergic projections from the PPN excite SNc-DA neurons.

Cholinergic PPN neurons also excite pontine reticular formation neurons, which, in turn, activate reticulospinal neurons in the medial medulla corresponding to the nucleus reticularis gigantocellularis

(NRGc). These descending tracts act on central pattern generator (CPG) in spinal cord to evoke locomotion. Efferents from the cerebellar locomotor region (CLR) may excite locomotor pathway.

B. Ventral system for emotional locomotor control. Efferents from the amygdala (AMD) and hippocampus (Hipp) project to the nucleus accumbens (NAC). GABAergic NAc neurons project to ventral pallidus (VP) and the SNr, which control activity of the MLR/PPN neurons. Efferents from the amygdala and the hippocampus also act on lateral hypothalamic area, which corresponds to the subthalamic locomotor region (SLR). DA projections from the ventral tegmental area (VTA) may contribute to the reward-oriented locomotor behaviors. See text for further details.

Abbreviations: E; extensor motoneurons, F; flexor motoneurons.

Figure 1

$387 \times 307 \mathrm{~mm}(300 \times 300$ DPI $)$ 

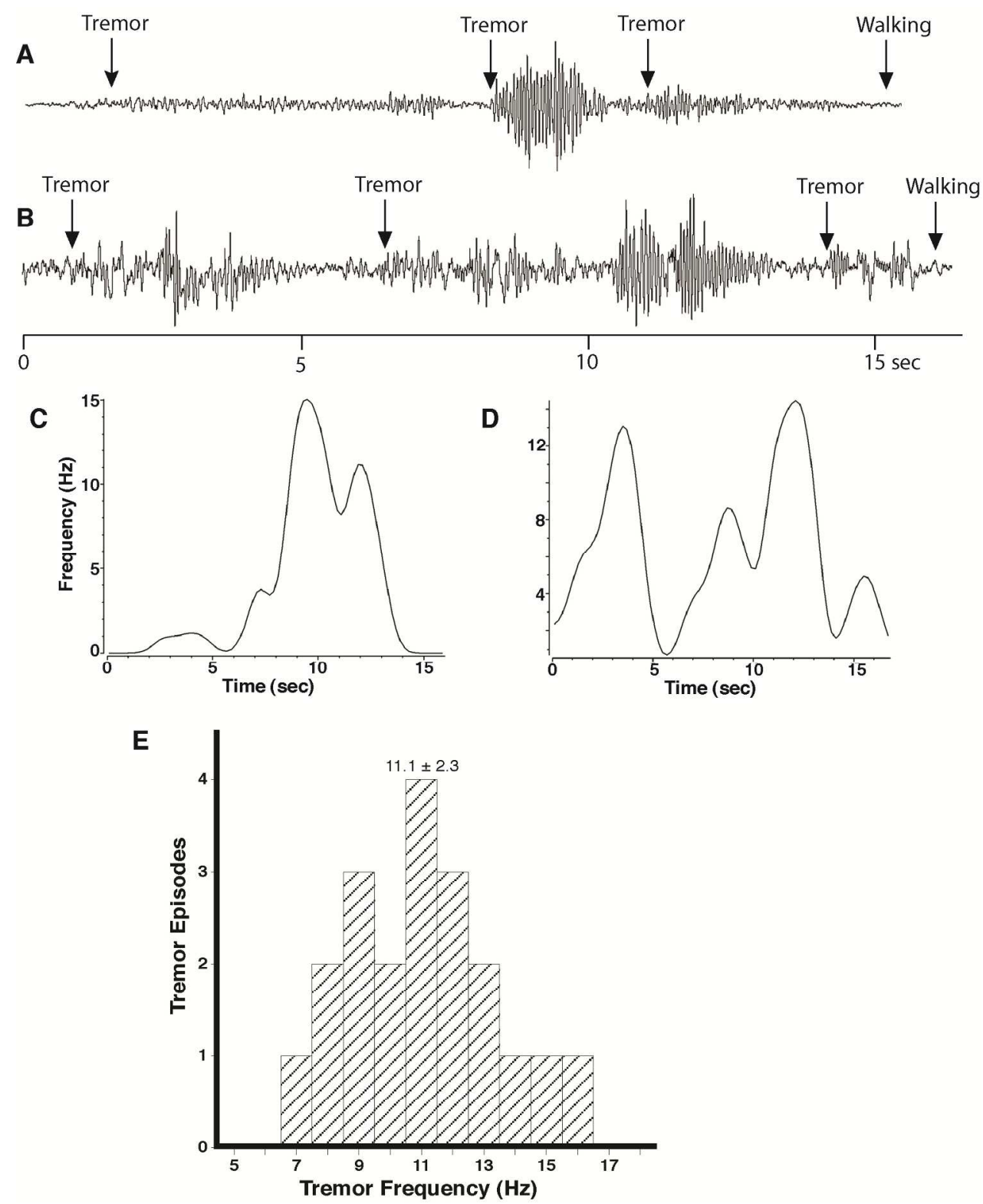

Figure 2: Analysis of the evolution of FOG episodes in the MPTP-treated monkey.

$A$ and $B$, recordings of leg movements with an accelerometer placed on the back of the leg during the whole duration of FOG episodes ( $\sim 15 \mathrm{~s})$. Each episode $(A$ and $B$ ) has regular oscillations corresponding to tremor before the end of freezing. The traces show raw accelerometry data. $C$ and $D$, rate meters for the whole duration of the FOG episodes corresponding to A and B, respectively. The peaks correspond to the tremor periods towards the end of the freezing episode when walk restarts and initial oscillatory movements. Rate meters used the data produced after detection of full phase oscillations above the threshold. The graphs were constructed with a bin width of 500 ms, and smoothed using a Gaussian filter. E, distribution of FOG tremor frequencies. The graph shows the frequencies $(\mathrm{Hz})$ found across 20 recordings of tremor, each in a separate FOG episode. The average rate in the recorded tremors was $7.07 \mathrm{~Hz}( \pm 1.47$ STD). Taken from

(Revuelta et al) with permission.

Figure 2

\section{John Wiley \& Sons}

This article is protected by copyright. All rights reserved. 


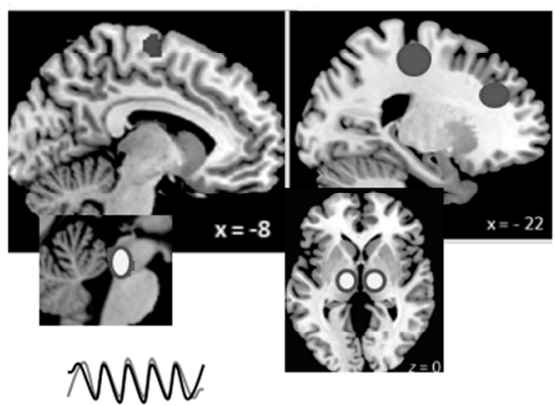

Continuous movement Cortical: SMA $\downarrow$ PFC $\downarrow$ Hands: STN Legs/gait: MLR

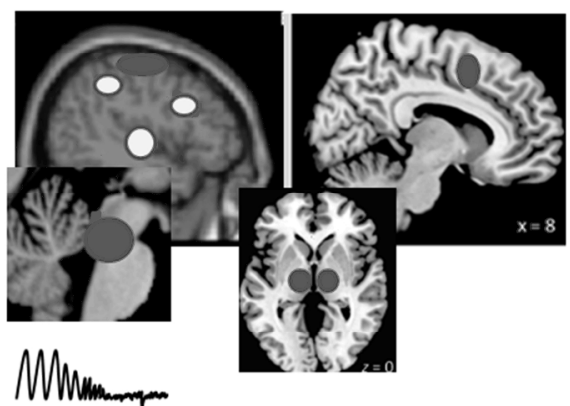

Freezing episode

SMA $\downarrow$ Frontoparietal $\uparrow$ Insula STN $\downarrow$ MLR $\downarrow$

Figure 3: Schematic cerebral substrate FOG following from fMRI studies

Figure 3:

Dynamic cerebral substrate of FOG, based on data from fMRI studies Snijders et al 2011, Vercruysse et al 2014, Shine et al 2013a and 2013b

- During repetitive continuous movement of hands or legs, or motor imagery of gait, cortical activity in areas as the SMA and PFC is reduced, while subcortical activity is increased; for the STN in the hands, in the MLR

for leg movents or imagery of gait. During a freezing episode, SMA activity is still reduced, but also subcortical areas STN and MLR show reduced activity. In contrast, frontoparietal areas and the insula show increased activity.

Abbreviations: SMA = supplementary motor area; PFC = prefrontal cortex; STN = subthalamic nucleus; MLR $=$ Mesencephalic locomotor region; DLPFC $=$ dorsolateral prefrontal cortex

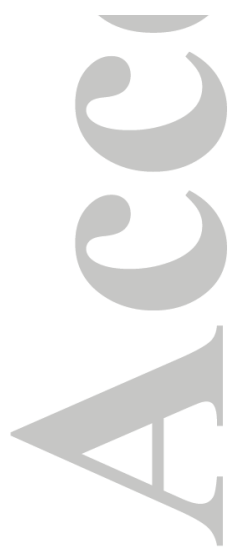

$254 \times 190 \mathrm{~mm}(300 \times 300 \mathrm{DPI})$ 
Activity counts with stimulation at different frequencies

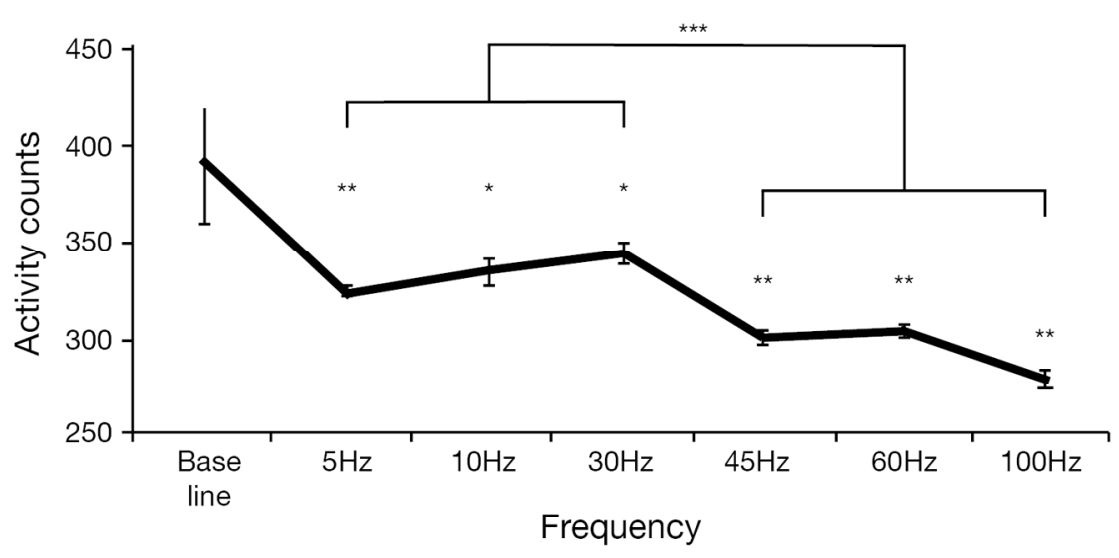

Figure 4: In normal macaque, multiple sessions of DBS unilateral PPN stimulation at several different frequencies: significant decrease in motor activity with higher frequency DBS (45 to $100 \mathrm{~Hz}$ ).

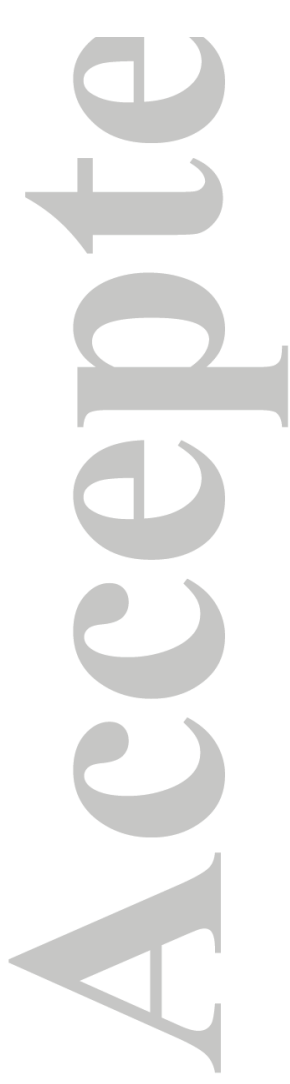

$161 \times 98 \mathrm{~mm}(300 \times 300$ DPI) 


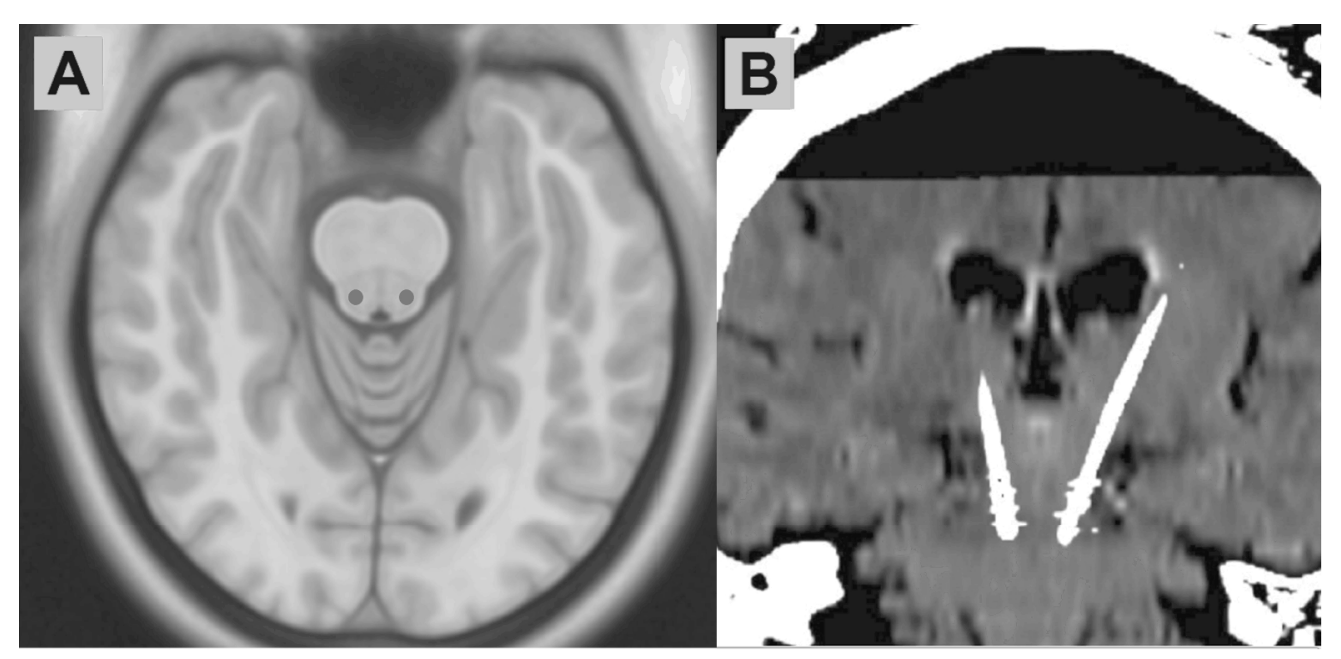

Figure 5:

(A) Location of the PPN identified on the ICBM 2009b NLIN T1 asymmetric template by Andreas Horn, Michael D. Fox and Clifford B. Saper, by transferring the location of ChAT-staining of neurons in the PPN in human brain 123 to standard atlas space using neuroanatomical landmarks.

(B) MRI with bilateral electrodes for stimulating the PPN. Note that to implant the PPN region the surgeon has to avoid traversing the lateral ventricles which would increase the risk of hemorrhage. To remain intraparenchymal the surgeon approaches the target calculating the azimuth and declination to place as many contacts in the PPN area as possible. (Part B courtesy of Dr. Peter Silburn, Brisbane Australia) !! +

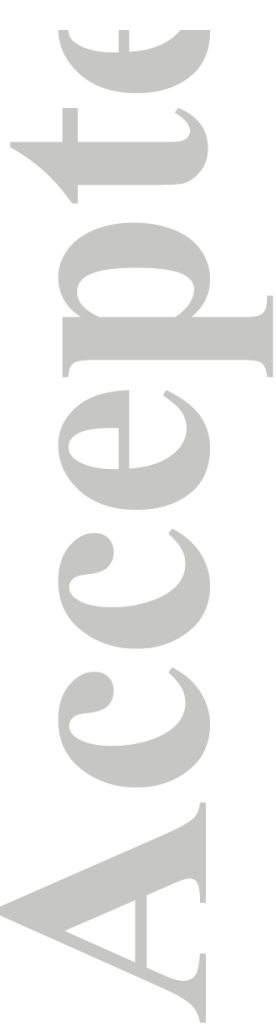

$323 \times 155 \mathrm{~mm}(300 \times 300 \mathrm{DPI})$ 